\title{
Coupled alkali feldspar dissolution and secondary mineral precipitation in batch systems: 4 . Numerical modeling of kinetic reaction paths
}

\author{
Chen Zhu ${ }^{\mathrm{a}, *}$, Peng Lu ${ }^{\mathrm{a}, 1}$, Zuoping Zheng ${ }^{\mathrm{a}}$, Jiwchar Ganor ${ }^{\mathrm{b}}$ \\ ${ }^{a}$ Department of Geological Sciences, Indiana University, Bloomington, IN 47405, USA \\ ${ }^{\mathrm{b}}$ Department of Geological and Environmental Sciences, Ben-Gurion University of the Negev, Beer-Sheva 84105, Israel
}

Received 6 August 2009; accepted in revised form 13 April 2010; available online 27 April 2010

\begin{abstract}
This paper explores how dissolution and precipitation reactions are coupled in batch reactor experimental systems at elevated temperatures. This is the fourth paper in our series of "Coupled Alkali Feldspar Dissolution and Secondary Mineral Precipitation in Batch Systems". In our third paper, we demonstrated via speciation-solubility modeling that partial equilibrium between secondary minerals and aqueous solutions was not attained in feldspar hydrolysis batch reactors at $90-300{ }^{\circ} \mathrm{C}$ and that a strong coupling between dissolution and precipitation reactions follows as a consequence of the slower precipitation of secondary minerals ( $\mathrm{Zhu}$ and $\mathrm{Lu}, 2009$ ). Here, we develop this concept further by using numerical reaction path models to elucidate how the dissolution and precipitation reactions are coupled. Modeling results show that a quasi-steady state was reached. At the quasi-steady state, dissolution reactions proceeded at rates that are orders of magnitude slower than the rates measured at far from equilibrium. The quasi-steady state is determined by the relative rate constants, and strongly influenced by the function of Gibbs free energy of reaction $\left(\Delta G_{\mathrm{r}}\right)$ in the rate laws.

To explore the potential effects of fluid flow rates on the coupling of reactions, we extrapolate a batch system (Ganor et al., 2007) to open systems and simulated one-dimensional reactive mass transport for oligoclase dissolution and kaolinite precipitation in homogeneous porous media. Different steady states were achieved at different locations along the one-dimensional domain. The time-space distribution and saturation indices (SI) at the steady states were a function of flow rates for a given kinetic model. Regardless of the differences in SI, the ratio between oligoclase dissolution rates and kaolinite precipitation rates remained 1.626, as in the batch system case (Ganor et al., 2007). Therefore, our simulation results demonstrated coupling among dissolution, precipitation, and flow rates.

Results reported in this communication lend support to our hypothesis that slow secondary mineral precipitation explains part of the well-known apparent discrepancy between lab measured and field estimated feldspar dissolution rates (Zhu et al., 2004). Here we show how the slow secondary mineral precipitation provides a regulator to explain why the systems are held close to equilibrium and show how the most often-quoted "near equilibrium" explanation for an apparent field-lab discrepancy can work quantitatively. The substantiated hypothesis now offers the promise of reconciling part of the apparent fieldlab discrepancy.
\end{abstract}

(c) 2010 Elsevier Ltd. All rights reserved.

\footnotetext{
* Corresponding author. Tel.: +1 8128561884 .

E-mail address: chenzhu@indiana.edu (C. Zhu).

${ }^{1}$ Now at: Calera Corporation, 14600 Winchester Boulevard, Los Gatos, CA 95032.
}

\section{INTRODUCTION}

Numerous hypotheses have been proposed in the literature to explain the persistent apparent discrepancy between measured field and laboratory feldspar dissolution rates (for the discrepancy, see Paces, 1973; Siegel and Pfannkuch, 
1984; Velbel, 1990; Brantley, 1992; Blum and Stillings, 1995; Drever and Clow, 1995). These hypotheses include the possible armoring effects of the secondary minerals that coat the feldspar grain surfaces (Correns and Von Engelhardt, 1938; Correns, 1940; Helgeson, 1971, 1972; Luce et al., 1972; Paces, 1973; Busenberg and Clemency, 1976; Chou and Wollast, 1984; Nugent et al., 1998), the possible effects of the leached layer (Luce et al., 1972; Busenberg and Clemency, 1976; Chou and Wollast, 1984; Hellmann et al., 1990; Brantley and Stillings, 1996; Hellmann, 1997; Nesbitt and Skinner, 2001; Oelkers, 2001), the approach to saturation with respect to feldspars (Burch et al., 1993; Gautier et al., 1994; Oelkers et al., 1994; Oelkers, 2001; Beig and Lüttge, 2006; Hellmann and Tisserand, 2006), unknown biological effects, and inhibition by adsorbed $\mathrm{Al}^{3+}$ on feldspar surfaces (Chou and Wollast, 1985; Gautier et al., 1994; Oelkers et al., 1994; Oelkers, 2001).

One distinction that differentiates field from laboratory conditions is that weathering product minerals are often intimately associated with the primary minerals in nature (Banfield and Eggleton, 1990; Banfield et al., 1991; Banfield and Barker, 1994; Nugent et al., 1998; Zhu et al., 2006; Hereford et al., 2007). Conversely, in laboratory experiments, the precipitation of product minerals was often avoided by adjusting the chemistry and recirculation rate of the fluid phase. Recognizing the close association between the secondary and primary minerals in the field, Zhu et al. (2004) proposed a new hypothesis (Zhu-Blum-Veblen or ZBV hypothesis hereafter) for explaining the laboratoryfield discrepancy wherein the slow kinetics of secondary clay precipitation is the rate limiting step and thus controls the overall feldspar dissolution rate. Clay precipitation removes solutes from the aqueous solution, maintaining a condition of feldspar undersaturation. This makes additional feldspar dissolution possible, but the slow clay precipitation (or smaller effective rate constants with respect to that for the dissolution reaction, see below) results in a quasi-steady state in which the aqueous solution is near equilibrium with feldspar. Therefore, slow clay precipitation could effectively reduce feldspar dissolution rates by orders of magnitude, in a fashion consistent with laboratory rates at conditions far from equilibrium, the control of dissolution rates by the Gibbs free energy of the reaction, and many field observations (Zhu et al., 2004).

To test this hypothesis, we have conducted experiments of feldspar dissolution and secondary mineral precipitation in batch systems. As these reactions are too slow to be measured under ambient temperature and circumneutral $\mathrm{pH}$ conditions (Ganor et al., 2007), the experiments were conducted at $200{ }^{\circ} \mathrm{C}$ and 300 bars. Although the secondary minerals formed in these high temperature experiments are different from clays formed under ambient, weathering temperatures, the failure to achieve partial equilibrium under hydrothermal conditions is highly likely an excellent indicator that partial equilibrium with secondary minerals is also not attained under weathering temperatures. In the first of this series of articles, we presented new experimental data, which documented the temporal evolution of aqueous chemistry and secondary minerals (Fu et al., 2009). The second paper is on $\mathrm{CO}_{2}$ effects on feldspar hydrolysis and it is still in preparation. The third paper described the saturation indices and reaction paths in terms of trajectories of aqueous chemical evolution on equilibrium activity-activity diagrams (Zhu and Lu, 2009). These articles document that secondary minerals were not at equilibrium with the aqueous solutions, but their precipitation was likely controlled by kinetic processes that are slower than the dissolution rates. Partial equilibrium between secondary minerals and aqueous solutions was not observed (Zhu and Lu, 2009).

In the present communication, we report results of numerical reaction path modeling that simulate the feldspar hydrolysis experiments by matching modeling results with experimental data. The reaction path modeling reported here is different from the speciation and solubility modeling in Paper 3 (Zhu and Lu, 2009). Speciation and solubility modeling simulates a snapshot of a chemical system while the reaction path modeling simulates processes. To simulate the experimental processes, reaction path models use the initial experimental solutions as a starting point. The course of the chemical evolution in the system is set by the rate laws for primary mineral dissolution and secondary mineral precipitation. In reaction path modeling, it is therefore necessary to make assumptions regarding reactive surface areas and the appropriate forms that the rate laws should take. Both topics are controversial and are presently undergoing intense research.

However, the reaction path models, reported here, give rich quantitative information of the reaction processes during these experiments. For example, the speciationsolubility modeling did not tell how the dissolution and precipitation reactions are coupled quantitatively, but reaction path modeling does, as shown in this paper. We should emphasize that the batch systems are simple model systems to test ideas of reaction kinetics before kinetic theories can be applied to complex natural systems, e.g., without further assumptions of flow and transport properties (Zhu, 2009). It is a necessary step in the process of going from laboratory dissolution rate experiments at far from equilibrium (e.g., mixed flow reactor with fixed solution chemistry) to natural systems. However, simulation of reactive mass transport in idealized model systems allows us to explore the potential effects of fluid flow rates on the coupling of dissolution and precipitation reactions.

\section{CONCEPTUAL MODELS AND ASSUMPTIONS}

The mathematical formulation of reaction path modeling has been extensively described before (Helgeson, 1968, 1979; Helgeson et al., 1969; Wolery, 1992). Essentially, for a geochemical system that has $n$ species, the following ordinary differential equations completely define the geochemical reaction network in a well-mixed reactor (Helgeson et al., 1970),

$\frac{\mathrm{d} m_{i}}{\mathrm{~d} t}=\sum_{j} v_{i, j} r_{i, j}, i \in n$

where $m_{i}$ denotes the concentrations of $i$ th species, $t$ the time, $v_{i, j}$ the stoichiometric coefficient for the $i$ th species in the $j$ th reaction, and $r_{i, j}$ the production or consumption rate of the $i$ th species in the $j$ th reaction. See Table 1 for symbols and notations. 
Table 1

List of symbols.

\begin{tabular}{ll}
\hline Symbols & Explanations \\
\hline $\mathrm{aq}$ & Subscript: aqueous species \\
$E_{\mathrm{a}}$ & Activation energy $\left(\mathrm{J} \mathrm{mol}^{-1}\right)$ \\
$g$ & $g \equiv\left|\Delta G_{\mathrm{r}}\right| / R T$ \\
$\Delta G_{\mathrm{r}, j}$ & Gibbs free energy of reaction for the $j$ th reaction $\left(\mathrm{J} \mathrm{mol}^{-1}\right)$ \\
$f\left(\Delta G_{\mathrm{r}}\right)$ & Function of Gibbs free energy of reaction in the rate law \\
$k^{*}$ & Effective rate constant \\
$k_{1}$ & Rate constant for the first term of the empirical parallel rate law of Burch et al. $(1993)\left(\mathrm{mol} \mathrm{s}^{-1} \mathrm{~m}^{-2}\right)$ \\
$k_{2}$ & Rate constant for the second term of the empirical parallel rate law of Burch et al. $(1993)\left(\mathrm{mol} \mathrm{s}^{-1} \mathrm{~m}^{-2}\right)$ \\
$k_{j}$ & Rate constant of $j$ th mineral reaction $\left(\mathrm{mol} \mathrm{s}^{-1} \mathrm{~m}^{-2}\right)$ \\
$K$ & Equilibrium constant \\
$m_{t, i}$ & Total concentrations of the ith aqueous constituent in molality \\
$m_{i}$ & Molality of the $i$ th aqueous species \\
$m_{1}$ & Empirical parameters fitted from experimental data for the first term of the empirical parallel rate law of Burch et al. \\
$m_{2}$ & $(1993)$ \\
& Empirical parameters fitted from experimental data for the second term of the empirical parallel rate law of Burch \\
$n_{1}$ & et al. (1993) \\
$N_{j}$ & Empirical parameters fitted from experimental data for the first term of the empirical parallel rate law of Burch et al. \\
$Q$ & (1993) \\
$r_{j}$ & Moles of mineral $j$, per kg of water \\
$S I$ & Activity quotient \\
$S_{j}$ & Rate of dissolution or precipitation of the $j$ th mineral in mol s $\mathrm{kgw}^{-1}$ (kgw = kg water) \\
$\sigma$ & Saturation index \\
$\epsilon$ & Surface area of the $j$ th mineral \\
Mineral abbreviations & Temkin coefficient in the rate law \\
\hline & Include \\
& Albite, Ab; sanidine, San; quartz, Qtz \\
&
\end{tabular}

The numerical techniques for solving this set of equations are well established (Wolery, 1992) and several computer codes are now available for performing the computation task. In our study, we used the computer code PhreeQc (Parkhurst and Appello, 1999), but with our own database for equilibrium constants at appropriate temperatures, pressures, and customized rate laws. In the reaction path models, we assumed that all homogenous reactions are instantaneous i.e., that all aqueous species are at equilibrium with each other. Aqueous speciation was modeled for all fluid samples taking explicit account of mass balance, mass action, and charge balance constraints. Activity coefficients for the charged aqueous species were calculated from the extended Debye-Hückel equation or B-dot equation fitted to mean salt $\mathrm{NaCl}$ activity coefficients (Helgeson et al., 1978; Oelkers and Helgeson, 1990). Activity coefficients for neutral or uncharged aqueous species were calculated from the Setchénow equation with a coefficient of 0.1 . Deviation from unity for activity coefficients for end-members of feldspar or clay solid solutions that result from compositional impurities was neglected. The rates of mass transfer between solid and aqueous phases are prescribed by the rate laws described below.

\subsection{Standard state thermodynamic data}

In all calculations, the standard states for solids are defined as unit activity for pure end-member solids at the temperature and pressure of interest. The standard state for water is the unit activity of pure water. For aqueous species other than $\mathrm{H}_{2} \mathrm{O}$, the standard state is the unit activity of the species in a hypothetical one molal solution referenced to infinite dilution at the temperature and pressure of interest. Equilibrium constants $(\log K)$ for reactions were calculated from the standard state thermodynamic properties for mineral end-members and aqueous species. The values of $\log K$ and the sources of thermodynamic properties that were used are listed in Table 2. In all cases, internally consistent thermodynamic properties were used when possible. See Zhu and $\mathrm{Lu}$ (2009) for a detailed discussion of the choices regarding standard thermodynamic properties.

\subsection{Rate laws}

A general form of rate laws for heterogeneous reactions may be written as (Lasaga et al., 1994),

$r_{j}=\frac{\mathrm{d} N_{j}}{\mathrm{~d} t}=k_{j} S_{j} a_{\mathrm{H}^{+}}^{n_{\mathrm{H}}^{+}} g(I) \prod_{a} a_{i}^{n_{i}} f\left(\Delta G_{\mathrm{r}}\right)$

where $r_{j}$ is the dissolution rate of the $j$ th mineral (mol s${ }^{-1} \mathrm{kgw}^{-1}$; $\mathrm{kgw}, \mathrm{kg}$ water), $N_{j}$ denotes the moles of mineral $j$ per $\mathrm{kg}$ of water $\left(\mathrm{mol} \mathrm{kgw}{ }^{-1}\right), k_{j}$ is the respective rate constant $\left(\mathrm{mol} \mathrm{s}^{-1} \mathrm{~m}^{-2}\right)$, and $S_{j}$ is the reactive surface area of the $j$ th mineral $\left(\mathrm{m}^{2} \mathrm{kgw}^{-1}\right) \cdot a_{H^{+}}$stands for the activity of hydrogen in the aqueous solution, and hence this term accounts for the well-noted $\mathrm{pH}$ dependence of dissolution rates. The term $g(I)$ accounts for possible ionic strength dependence of the rates. The term $\prod_{a} a_{i}^{n_{i}}$ incorporates possible catalytic and inhibitory effects of aqueous species. $\Delta G_{\mathrm{r}}\left(\mathrm{J} \mathrm{mol}^{-1}\right)$ denotes the Gibbs free energy of reaction.

The term $f\left(\Delta G_{\mathrm{r}}\right)$ describes the effect of deviation from equilibrium on the rate and represents the thermodynamic 
Table 2

Equilibrium constants used in this study.

\begin{tabular}{|c|c|c|c|c|}
\hline & $25^{\circ} \mathrm{C}, 1$ bar & $200^{\circ} \mathrm{C}, 300$ bars & $300^{\circ} \mathrm{C}, 88$ bars & Reference \\
\hline \multicolumn{5}{|l|}{ Aqueous reactions } \\
\hline $\mathrm{H}_{2} \mathrm{O}=\mathrm{OH}^{-}+\mathrm{H}^{+}$ & -13.995 & -11.163 & -11.297 & $(1)$ \\
\hline $\mathrm{Al}^{3+}+\mathrm{H}_{2} \mathrm{O}=\mathrm{Al}(\mathrm{OH})^{2+}+\mathrm{H}^{+}$ & -4.964 & -1.446 & -0.22 & (2) \\
\hline $\mathrm{Al}^{3+}+2 \mathrm{H}_{2} \mathrm{O}=\mathrm{Al}(\mathrm{OH})_{2}^{+}+2 \mathrm{H}^{+}$ & -10.921 & -3.63 & -1.119 & $(2)$ \\
\hline $\mathrm{Al}^{3+}+3 \mathrm{H}_{2} \mathrm{O}=\mathrm{Al}(\mathrm{OH})_{3}{ }^{\mathrm{o}}+3 \mathrm{H}^{+}$ & -17.044 & -7.301 & -4.035 & $(2)$ \\
\hline $\mathrm{Al}^{3+}+4 \mathrm{H}_{2} \mathrm{O}=\mathrm{Al}(\mathrm{OH})_{4}^{-}+4 \mathrm{H}^{+}$ & -22.851 & -11.572 & -8.150 & $(2)$ \\
\hline $\mathrm{Al}^{3+}+\mathrm{Na}^{+}+4 \mathrm{H}_{2} \mathrm{O}=\mathrm{NaAl}(\mathrm{OH})_{4}{ }^{\mathrm{o}}+4 \mathrm{H}^{+}$ & -22.90 & -10.748 & -6.63 & (2) \\
\hline $\mathrm{Al}^{3+}+\mathrm{SiO}_{2}{ }^{\circ}+2 \mathrm{H}_{2} \mathrm{O}=\mathrm{AlH}_{3} \mathrm{SiO}_{4}{ }^{2+}+\mathrm{H}^{+}$ & -2.357 & 1.86 & 3.188 & $(2)$ \\
\hline $\mathrm{Na}^{+}+\mathrm{H}_{2} \mathrm{O}=\mathrm{NaOH}^{\mathrm{o}}+\mathrm{H}^{+}$ & -14.205 & -11.087 & -10.480 & (3) \\
\hline $\mathrm{SiO}_{2}{ }^{\mathrm{o}}+\mathrm{H}_{2} \mathrm{O}=\mathrm{HSiO}_{3}{ }^{-}+\mathrm{H}^{+}$ & -9.585 & -8.707 & -9.430 & (3) \\
\hline $\mathrm{SiO}_{2}{ }^{\mathrm{o}}+\mathrm{Na}^{+}+\mathrm{H}_{2} \mathrm{O}=\mathrm{NaHSiO}_{3}{ }^{\circ}+\mathrm{H}^{+}$ & -7.754 & -7.767 & -7.986 & (3) \\
\hline $\mathrm{Ca}^{2+}+\mathrm{H}_{2} \mathrm{O}=\mathrm{CaOH}^{+}+\mathrm{H}^{+}$ & -12.833 & -7.961 & -6.435 & (3) \\
\hline $\mathrm{K}^{+}+\mathrm{H}_{2} \mathrm{O}=\mathrm{KOH}^{\mathrm{o}}+\mathrm{H}^{+}$ & -14.439 & -10.939 & -10.267 & (3) \\
\hline $\mathrm{Cl}^{-}+\mathrm{Ca}^{2+}=\mathrm{CaCl}^{+}$ & -0.292 & 1.146 & & (3) \\
\hline $2 \mathrm{Cl}^{-}+\mathrm{Ca}^{2+}=\mathrm{CaCl}_{2}^{\circ}$ & -0.644 & 0.672 & & (3) \\
\hline $\mathrm{H}^{+}+\mathrm{Cl}^{-}=\mathrm{HCl}^{\mathrm{o}}$ & -0.710 & -0.15 & & (4) \\
\hline $\mathrm{K}^{+}+\mathrm{Cl}^{-}=\mathrm{KCl}^{\mathrm{o}}$ & & 0.456 & & (5) \\
\hline $\mathrm{Na}^{+}+\mathrm{Cl}^{-}=\mathrm{NaCl}^{\circ}$ & -0.777 & 0.019 & & (3) \\
\hline $\mathrm{HCO}_{3}{ }^{-}+\mathrm{H}^{+}=\mathrm{CO}_{2}+\mathrm{H}_{2} \mathrm{O}$ & 6.345 & & 8.525 & (3) \\
\hline $\mathrm{HCO}_{3}^{-}=\mathrm{CO}_{3}^{2-}+\mathrm{H}^{+}$ & -10.329 & & -11.461 & (3) \\
\hline $\mathrm{HCO}_{3}{ }^{-}+\mathrm{Na}^{+}=\mathrm{NaCO}_{3}{ }^{-}+\mathrm{H}^{+}$ & -9.455 & & -8.468 & $(8)$ \\
\hline $\mathrm{HCO}_{3}^{-}+\mathrm{Na}^{+}=\mathrm{NaHCO}_{3}{ }^{\circ}$ & -0.103 & & 2.002 & $(8)$ \\
\hline $\mathrm{HCO}_{3}^{-}+\mathrm{K}^{+}=\mathrm{KCO}_{3}^{-}+\mathrm{H}^{+}$ & -9.455 & & -8.468 & $(8)$ \\
\hline $\mathrm{HCO}_{3}^{-}+\mathrm{K}^{+}=\mathrm{KHCO}_{3}{ }^{\circ}$ & -0.103 & & 2.002 & $(8)$ \\
\hline \multicolumn{5}{|l|}{ Mineral dissolution reactions } \\
\hline $\mathrm{NaAlSi}_{3} \mathrm{O}_{8}$ (albite) $+4 \mathrm{H}^{+}=\mathrm{Al}^{3+}+\mathrm{Na}^{+}+3 \mathrm{SiO}_{2}{ }^{\mathrm{o}}+2 \mathrm{H}_{2} \mathrm{O}$ & 2.065 & -2.508 & -4.714 & $(6)$ \\
\hline $\mathrm{AlO}_{2} \mathrm{H}$ (boehmite) $+3 \mathrm{H}^{+}=\mathrm{Al}^{3+}+2 \mathrm{H}_{2} \mathrm{O}$ & 7.610 & 0.242 & -2.530 & (7) \\
\hline $\mathrm{AlO}_{2} \mathrm{H}($ diaspore $)+3 \mathrm{H}^{+}=\mathrm{Al}^{3+}+2 \mathrm{H}_{2} \mathrm{O}$ & 7.191 & 0.02 & -2.685 & $(6)$ \\
\hline $\mathrm{Al}_{2} \mathrm{Si}_{2} \mathrm{O}_{5}(\mathrm{OH})_{4}$ (kaolinite) $+6 \mathrm{H}^{+}=2 \mathrm{Al}^{3+}+2 \mathrm{SiO}_{2}{ }^{\mathrm{o}}+5 \mathrm{H}_{2} \mathrm{O}$ & 4.501 & -5.354 & -9.443 & (6) \\
\hline $\mathrm{KAlSi}_{3} \mathrm{O}_{8}$ (microcline) $+4 \mathrm{H}^{+}=\mathrm{Al}^{3+}+\mathrm{K}^{+}+3 \mathrm{SiO}_{2}{ }^{\mathrm{o}}+2 \mathrm{H}_{2} \mathrm{O}$ & -1.05 & -3.923 & -5.694 & (6) \\
\hline $\begin{array}{l}\mathrm{KAl}_{3} \mathrm{Si}_{3} \mathrm{O}_{10}(\mathrm{OH})_{2} \\
\text { (muscovite) }+10 \mathrm{H}^{+}=\mathrm{K}^{+}+3 \mathrm{Al}^{3+}+3 \mathrm{SiO}_{2}^{\mathrm{o}}+6 \mathrm{H}_{2} \mathrm{O}\end{array}$ & 11.22 & -5.407 & -12.445 & (6) \\
\hline $\begin{array}{l}\mathrm{NaAl}_{3} \mathrm{Si}_{3} \mathrm{O}_{10}(\mathrm{OH})_{2} \\
\text { (paragonite) }+10 \mathrm{H}^{+}=\mathrm{Na}^{+}+3 \mathrm{Al}^{3+}+3 \mathrm{SiO}_{2}{ }^{\mathrm{o}}+6 \mathrm{H}_{2} \mathrm{O}\end{array}$ & 14.397 & -3.753 & -11.164 & $(6)$ \\
\hline $\mathrm{Al}_{2} \mathrm{Si}_{4} \mathrm{O}_{10}(\mathrm{OH})_{2}$ (pyrophyllite) $+6 \mathrm{H}^{+}=2 \mathrm{Al}^{3+}+4 \mathrm{H}_{2} \mathrm{O}+4 \mathrm{SiO}_{2}{ }^{\mathrm{o}}$ & -1.724 & -9.733 & -13.647 & $(6)$ \\
\hline $\mathrm{SiO}_{2}(\mathrm{Quartz})=\mathrm{SiO}_{2}{ }^{\circ}$ & -4.047 & -2.424 & -2.033 & (6) \\
\hline $\mathrm{KAlSi}_{3} \mathrm{O}_{8}$ (sanidine) $+4 \mathrm{H}^{+}=\mathrm{Al}^{3+}+\mathrm{K}^{+}+3 \mathrm{SiO}_{2}{ }^{\mathrm{o}}+2 \mathrm{H}_{2} \mathrm{O}$ & -0.002 & & -5.499 & (6) \\
\hline $\mathrm{KAlSiO}_{4}$ (kalsilite) $+4 \mathrm{H}^{+}=\mathrm{K}^{+}+\mathrm{Al}^{3+}+\mathrm{SiO}_{2}{ }^{\circ}+2 \mathrm{H}_{2} \mathrm{O}$ & 12.543 & & 1.187 & $(6)$ \\
\hline $\mathrm{NaAlSiO}_{4}$ (nepheline) $+4 \mathrm{H}^{+}=\mathrm{Na}^{+}+\mathrm{Al}^{3+}+\mathrm{SiO}_{2}{ }^{\mathrm{o}}+2 \mathrm{H}_{2} \mathrm{O}$ & 13.423 & & 1.185 & (6) \\
\hline
\end{tabular}

(1) Haar et al. (1984); (2) Tagirov and Schott (2001); (3) Sverjensky et al. (1997); (4) McCollom and Shock (1997); (5) Ho et al. (2000); (6) Holland and Powell (1998) for minerals and (1), (2), and (3) for aqueous species; (7) Hemingway et al. (1991) for boehmite; (8) Alekseyev et al. (1997).

driving force for chemical reactions (Prigogine and Defay, 1965; Aagaard and Helgeson, 1982). A simple form for the $r_{j}-\Delta G_{\mathrm{r}}$ relationship is proposed based on the transition state theory (TST) (Lasaga, 1981a,b; Aagaard and Helgeson, 1982),

$f\left(\Delta G_{\mathrm{r}}\right)=\left(1-\exp \left(\frac{\Delta G_{\mathrm{r}}}{R T}\right)\right)$

This formulation of the free energy term has also been termed the "linear TST rate law" because the relationship between $r_{j}$ and $\Delta G_{\mathrm{r}}$ becomes linear near equilibrium.

However, a number of experiments near equilibrium have shown that the actual relationship between $r_{j}$ and $\Delta G_{\mathrm{r}}$ deviates from this so-called linear kinetics (Schramke et al., 1987; Nagy et al., 1991; Nagy and Lasaga, 1992, 1993; Burch et al., 1993; Gautier et al., 1994; Alekseyev et al., 1997; Cama et al., 2000; Taylor et al., 2000; Beig and Lüttge, 2006; Hellmann and Tisserand, 2006). As shown below, the linear TST rate law also cannot fit the experimental data of $\mathrm{Zhu}$ and $\mathrm{Lu}$ (2009).

Different non-linear rate laws were proposed for feldspar dissolution. For example, Alekseyev et al. (1997) introduced a non-linear rate law in the form of,

$f\left(\Delta G_{\mathrm{r}}\right)=\left|1-\left(\frac{Q}{K}\right)^{p}\right|^{q}$

where $Q$ is the activity quotient, $K$ is the equilibrium constant, $p$ and $q$ are fitting parameters. Burch et al. (1993) proposed an empirical parallel rate law in the form of,

$r / S=k_{1}\left[1-\exp \left(-n_{1} g^{m_{1}}\right)\right]+k_{2}[1-\exp (-g)]^{m_{2}}$

where $k_{1}$ and $k_{2}$ denote the rate constants in units of mol s${ }^{-1} \mathrm{~m}^{-2}, g \equiv\left|\Delta G_{\mathrm{r}}\right| / R T$, and $n_{1}, m_{1}$, and $m_{2}$ are empirical parameters fitted from experimental data. Note that the 
first term is equivalent to Eq. (4) if $n_{1}=p, m_{1}=1$, and $q=1$. The second term is also equivalent to Eq. (4) if $p=1$ and $m_{2}=q$. In the reaction path modeling of the present study, the rate law of Eq. (5) is used for albite and oligoclase dissolution. Rate laws for other mineral dissolution and precipitation reactions will be discussed below as they appear.

\subsection{Reactive surface area}

The concept of "reactive surface area (RSA)" (Helgeson et al., 1984) is rooted in the theories of surface controlled reaction kinetics. The rates of heterogeneous reactions are proportional to the "concentrations" of reactive surface sites. The RSA thus substitutes for site concentrations in lieu of reactant concentrations in a first order rate law (Zhu and Anderson, 2002). Apparently, RSA represents the key scaling parameter for extrapolating from atomic to laboratory and field scales. However, this concept is difficult to implement in practice. Different crystal faces have different types of surface sites and site concentrations. Surface topography (e.g., kinks, edges, and adatoms) and types and densities of defects on mineral surfaces are difficult to quantify. The "reactive site concentrations" would also depend on whether and how deep a "leached layer" is developed near the mineral surfaces (Stillings et al., 1995; Oelkers, 2001).

The common practice in geochemistry is to use the Brunauer-Emmett-Teller (BET) surface area (Braunauer et al., 1938) of the dry powder as a proxy for the RSA. However, there are several challenges in substituting BET surface area for RSA in Eq. (2). From a theoretical point of view, we are using a single parameter to represent a variety of surface sites with different reactivity and concentrations. The BET SA is more physically based (gas adsorption and surface roughness) than chemical in nature. From a practical point of view, it is difficult to measure BET SA for a mineral within a mixture and for secondary minerals with miniature quantities. Often, the reactive surface areas are significantly less than the BET surface area (Helgeson et al., 1984).

In an experiment, reactive surface area may vary due to the growth or reduction of crystal sizes. In such cases, $S$ during dissolution or precipitation may be empirically related to the initial total surface area $\left(S^{\circ}\right)$ by (Christoffersen and Christoffersen, 1976; Witkamp et al., 1990; Zhang and Nancollas, 1992; He et al., 1994)

$S / S^{\mathrm{o}}=\left(N^{t} / N^{\mathrm{o}}\right)^{P}$

where $P$ is a coefficient that depends on the shape of the crystal and the relative rates of dissolution (or growth) on different surfaces. $P$ equals to $2 / 3$ if the shape of the crystals remains unchanged and rates on all faces are equal. $P$ values of 0.5 indicate that dissolution or growth occur predominantly in two directions while $P$ values of 0 indicate one direction (e.g., Witkamp et al., 1990).

The reactive surface areas may also vary during experiments as a result of the extinction of highly reactive fine particles (Helgeson et al., 1984), change of the ratios of reactive and nonreactive sites (Gautier et al., 2001), mechanical disaggregation of particles (Nagy and Lasaga,
1992; Ganor et al., 1999), and formation of surface coating (Ganor et al., 1995; Nugent et al., 1998; Cubillas et al., 2005; Metz et al., 2005).

It is even more difficult to estimate the reactive surface areas for precipitating secondary phases. Precipitation of a new mineral phase requires nucleation and crystal growth. Currently, the lack of parameters prevents the application of nucleation theories to the experiments that we examined in this study (see review by Fritz and Noguera, 2009). For modeling, it also presents a dilemma: precipitation cannot proceed without surface area first; and without precipitates at first, there are no surface areas for the secondary phases. Although the size of stable nuclei can be calculated using classical nucleation theory (Nielsen, 1964), there are no strict ways to assess the reactivity of such nuclei.

In this study, we followed common practice in geochemistry and used the BET surface areas for starting reactants in the reaction path modeling as the initial conditions. Then, we assessed the possible temporal variation of reactive surface areas from experimental data. When it was difficult to separate the effects of rate constant and reactive surface areas from batch reactor data, we introduced an effective rate constant, $k^{*}$

$k^{*}=k \times S$

where $S$ stands for reactive surface area. $k^{*}$ has a unit of $\mathrm{mol} \mathrm{s}{ }^{-1} \mathrm{kgw}^{-1}$ if $S$ has units of $\mathrm{m}^{2} \mathrm{kgw}^{-1}$. Note that $k^{*}$, as a fitting parameter, in effect, could represent all terms in the empirical rate law (Eq. (5)), except for the Gibbs free energy term and other effects explicitly noted.

\section{MODELING RESULTS AND ANALYSES}

\subsection{Albite dissolution-sanidine precipitation experiments}

Alekseyev et al. (1997) conducted a series of batch experiments for low albite $\left(\mathrm{Na}_{0.97} \mathrm{~K}_{0.02} \mathrm{AlSi}_{3.01} \mathrm{O}_{8}\right)$ dissolution in $0.1 \mathrm{~m} \mathrm{KHCO}$ fluid. The experiments were conducted at $300{ }^{\circ} \mathrm{C}$ and 88 bars and $\mathrm{pH} \sim 9.0$ (buffered by bicarbonate). The measured initial BET specific surface areas are $0.12 \mathrm{~m}^{2} \mathrm{~g}^{-1}$ for albite reactants. XRD and SEM results show that the only secondary mineral formed was sanidine.

Alekseyev et al. (1997, shortened to Alek97) calculated albite dissolution rates at the congruent stage (the first $7 \mathrm{~h}$, cf. their Fig. 2) on the basis of molal concentrations of $\mathrm{Na}, \mathrm{Al}$, and $\mathrm{Si}$ in the solutions, which are almost stoichiometric. At the incongruent stages (7-1848 h), they used a mass balance approach that accounts for primary mineral dissolution and secondary mineral precipitation to calculate reaction rates, which is essentially numerical inverse mass balance modeling but with statistical rigor. For convenience, we will reference the original values of rates, rate constants, mineral abundances etc. reported by Alek97 as "experimental data" although many of these values were derived and not directly measured.

\subsubsection{Congruent dissolution stage $(0-7 \mathrm{~h})$}

The first $7 \mathrm{~h}$ of the $1848 \mathrm{~h}$ experiments, according to Alek97, showed essentially congruent dissolution of albite. That was based on the stoichiometric ratios of $\mathrm{Na}, \mathrm{Al}$, and 

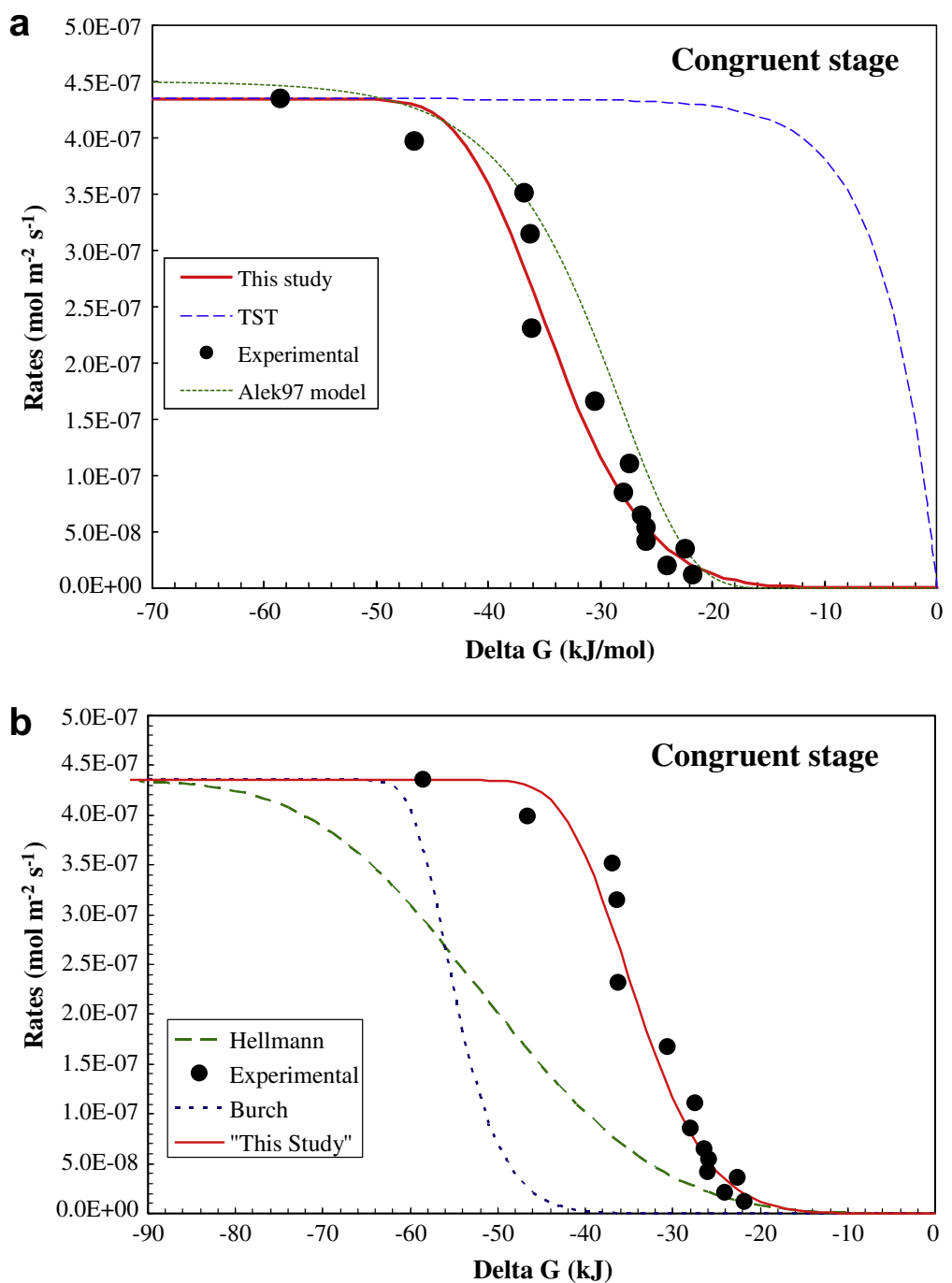

Fig. 1. Rates of albite dissolution in the first $7 \mathrm{~h}$ of experiments normalized to the initial BET surface areas (in mol $\mathrm{m}^{-2} \mathrm{~s}^{-1}$ ). Symbols denote experimental rates (Table 3 of Alekseyev et al., 1997) and lines indicate different rate law expressions. Delta G values were calculated in Zhu and $\mathrm{Lu}$ (2009). (a) The solid line represents rate law used in this study (Eq. (5)) with customized parameters. The dashed and dotted lines are based on linear rate law (TST) and rate expressions from Alekseyev et al. (1997), respectively. (b) The dotted and dashed lines denote calculated rates based on parameters from Burch et al. (1993) and Hellmann and Tisserand (2006), respectively.

Si released into the solution (see below) and on the lack of detectable sanidine in the reaction products. The experiments started far from equilibrium, and congruent dissolution of albite was recorded in the $\Delta G_{\mathrm{r}, \mathrm{Ab}}$ range from -59 to ca. $-20 \mathrm{~kJ} \mathrm{~mol}^{-1}$ (Fig. 1a). The initial mass/volume ratio in the experiment was $2.5 \mathrm{~g}$ albite $\mathrm{kgw}^{-1}\left(9.52 \times 10^{-3}\right.$ mol kgw ${ }^{-1}$ ) and the initial specific BET surface area was $0.12 \mathrm{~m}^{2} \mathrm{~g}^{-1}$. During the first $7 \mathrm{~h}$, about $8 \%$ of the albite was dissolved. The amounts of remaining albite $N$ (mol $\mathrm{kgw}^{-1}$ ) at the time of interest were roughly estimated from the mass balance,

$N^{i} \approx N^{i-1}-\left[r^{i} \times\left(t^{i}-t^{i-1}\right)\right]$

where $i$ stands for the $i$ th sample in the batch series, $t$ for time (s) and $r$ for the rate of dissolution in units of mol s${ }^{-1} \mathrm{kgw}^{-1}$ as reported by Alek97. The amount of albite was reduced to $\sim 8.8 \times 10^{-3} \mathrm{~mol}$ at $7 \mathrm{~h}$ according to Eq. (8).
It must be emphasized that Eq. (8) only gives rough estimates of the albite mass in the reactor. For simplicity, we assumed that the total surface area of albite $S_{\mathrm{Ab}}$ remained constant during the first $7 \mathrm{~h}$. This assumption resulted in an underestimation of the dissolution rate towards the end of $7 \mathrm{~h}$.

The experimental data allowed the fitting of $k_{1}, m_{1}$ and $n_{1}$ in Eq. (5). The fitted $k_{1}$ value $\left(4.35 \times 10^{-7} \mathrm{~mol} \mathrm{~s}^{-1} \mathrm{~m}^{-2}\right)$ at far from equilibrium condition (i.e., at $\Delta G_{\mathrm{r}, \mathrm{Ab}}=-59$ $\mathrm{kJ} \mathrm{mol}^{-1}$ ) is consistent with the independent data of Hellmann (1994) for Amelia albite $(\log k=-6.2$ or $k=$ $6.3 \times 10^{-7} \mathrm{~mol} \mathrm{~s}^{-1} \mathrm{~m}^{-2}$ at $\mathrm{pH} 8.6$ and $\left.300^{\circ} \mathrm{C}\right)$. To fit the shape of the $r-\Delta G_{\mathrm{r}, \mathrm{Ab}}$ curve, we used $m_{1}=6$ and $n_{1}=$ $5 \times 10^{-6}$. Because all experimental data were in the range $\Delta G_{\mathrm{r}, \mathrm{Ab}}<-16 \mathrm{~kJ} \mathrm{~mol}^{-1}$, the second term of Eq. (5) could not be determined with the Alek97 data. Fig. 1a compares the predicted change in the albite dissolution rate $(r)$ vs. 

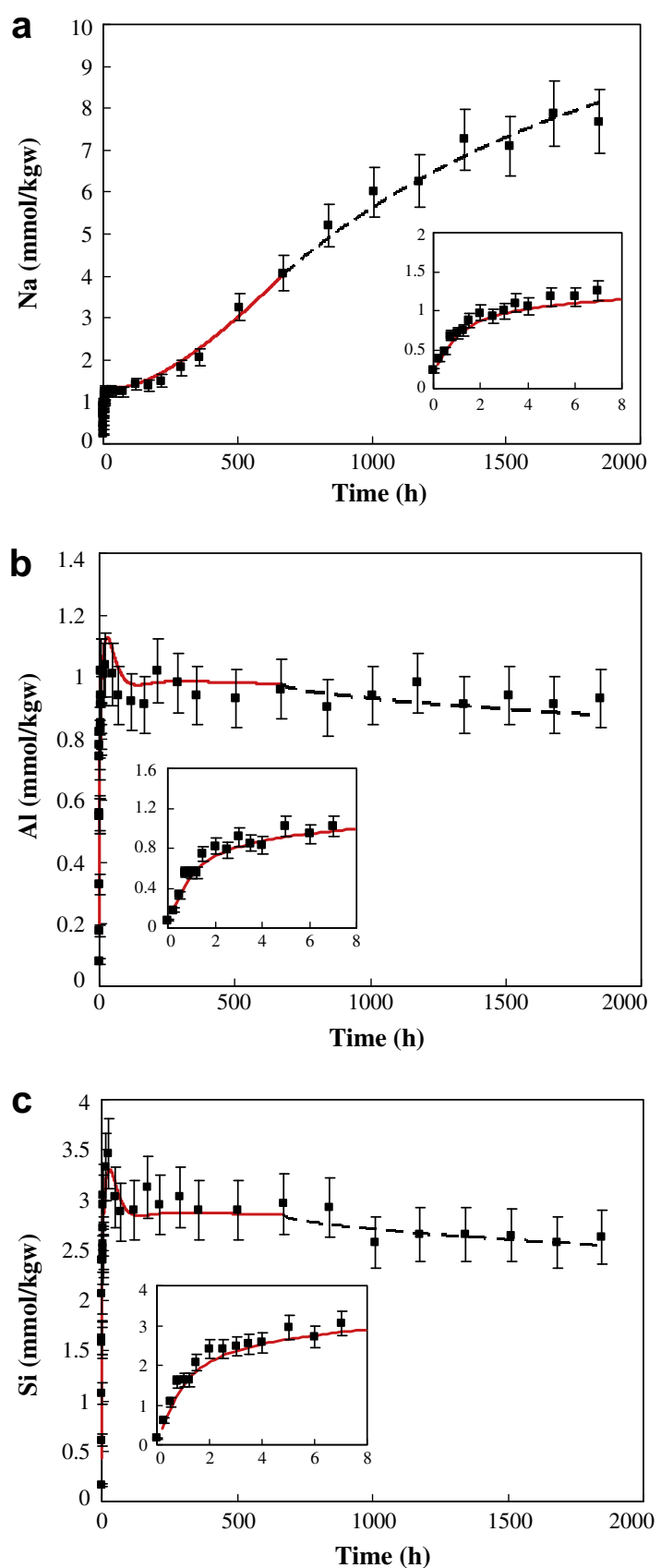

Fig. 2. Temporal evolution of dissolved constituent concentrations: (a) Na; (b) Al, and (c) Si. Symbols denote experimental data; lines results from numerical reaction path model simulation. The portion of dotted line shows the simulation results during 672 $1848 \mathrm{~h}$. Error bars indicate 10\% uncertainty in analytical measurements (the same hereafter).

deviation from equilibrium $\left(\Delta G_{\mathrm{r}, \mathrm{Ab}}\right)$ to the experimental observations and to the rate laws of Alek97 and TST.

Note that the $r-\Delta G_{\mathrm{r}, \mathrm{Ab}}$ curve (dotted curve in Fig. 1a) calculated with Alek97's rate law (Eq. (4)), slightly overpredicted the experimental data while it matched well with their Fig. 7. This is because we re-calculated the $\Delta G_{\mathrm{r}, \mathrm{Ab}}$ values with a different thermodynamic database ( $\mathrm{Zhu}$ and $\mathrm{Lu}$, 2009), which shifted the data points $\sim 4.34 \mathrm{~kJ} \mathrm{~mol}^{-1}$ towards lower $\Delta G_{\mathrm{r}, \mathrm{Ab}}$. The parameters we used for the first term $\left(k_{1}, m_{1}\right.$, and $\left.n_{1}\right)$ yielded a slightly better fitting of albite rates as a function of $\Delta G_{\mathrm{r}, \mathrm{Ab}}$ than the rate law of Alek97 recalculated with our thermodynamic database (Fig. 1a). Although both Eqs. (4) and (5) fit the experimental $r=f\left(\Delta G_{\mathrm{r}}\right)$ data well and both show asymptotical behavior, the predicted rates closer to equilibrium are quite different, with Eq. (4) predicting impossibly slow rates toward equilibrium as a result of its mathematical form. These slow rates do not agree with experimental data of Burch et al. (1993), Taylor et al. (2000), and Beig and Lüttge (2006) (cf. Fig. 6 of Zhu, 2009). The TST linear rate law (i.e., Eq. (3)), fitted to the initial rate constant far from equilibrium, led to serious over-estimation of dissolution rates at near equilibrium (dashed line in Fig. 1a).

The experimental data described a sigmoidal shape for the $r=f\left(\Delta G_{\mathrm{r}}\right)$ function. Burch et al. (1993) showed a steep slope for albite dissolution at $80^{\circ} \mathrm{C}$ and $\mathrm{pH} 8.8$ while Hellmann and Tisserand (2006) proposed a gentler slope for albite dissolution at $150{ }^{\circ} \mathrm{C}$ and $\mathrm{pH} 9.2$. Neither of their $m_{1}$ and $n_{1}$ pairs would fit the experimental $r-\Delta G_{\mathrm{r}, \mathrm{Ab}}$ data (Fig. 1b).

In short, the experimental data for congruent dissolution of albite in the first $7 \mathrm{~h}$ have adequately defined $k$, and, to some extent, a sigmoidal $r=f\left(\Delta G_{\mathrm{r}}\right)$. It is clear that the experimental data cannot be represented by a linear TST rate law. It is also clear that the rate law proposed by Alek97 (Eq. (4)) and regressed from the 0 to $7 \mathrm{~h}$ experimental data predicts unrealistically slow rates close to equilibrium. We will demonstrate, below, that the sigmoidal $r-\Delta G_{\mathrm{r}, \mathrm{Ab}}$ plays a significant role in defining how the reactions are coupled and how the ZBV hypothesis can be applied to field data. However, we must remember Eq. (5) is an empirical expression. In Section 3.2, we will add the parameters of the second term in Eq. (5), which only affects the later (and closer to equilibrium) period of the experiment.

Note that it is well-known that pristine fresh feldspar surfaces undergo rapid ion-exchange with cations (e.g., $\mathrm{K}^{+}, \mathrm{H}_{3} \mathrm{O}^{+}$) in the solution at the onset of the experiments (e.g., Garrels and Howard, 1957). This phenomenon was also observed in the Alek97 experiments. Alek97 attributed $0.18 \mathrm{mmol} \mathrm{kgw}^{-1} \mathrm{Na}^{+}$in the first fluid sample from these surface exchanges as well as impurity in chemical regents, and subtracted it in the rate calculations. We followed Alek97 in the reaction path simulations described below. Also note that the term "ion-exchange" in the literature sometimes also refers to replacement reactions (see Section 3.1.2).

\subsubsection{Steady state dissolution of albite and precipitation of sanidine $(\sim 672-1848 \mathrm{~h})$}

During the second stage of the experiment (7-672 h), sanidine nucleation occurred, which was followed by its precipitation. As geochemical models are currently limited in dealing with nucleation, we will first discuss here the last stage of the experiment (672-1848 h). During this stage, the system was in a quasi-steady state, during which concentrations of some elements (e.g., Al and $\mathrm{Si}$ ) but not all (e.g., Na) were almost constant (Fig. 2). The rates of albite dissolu- 


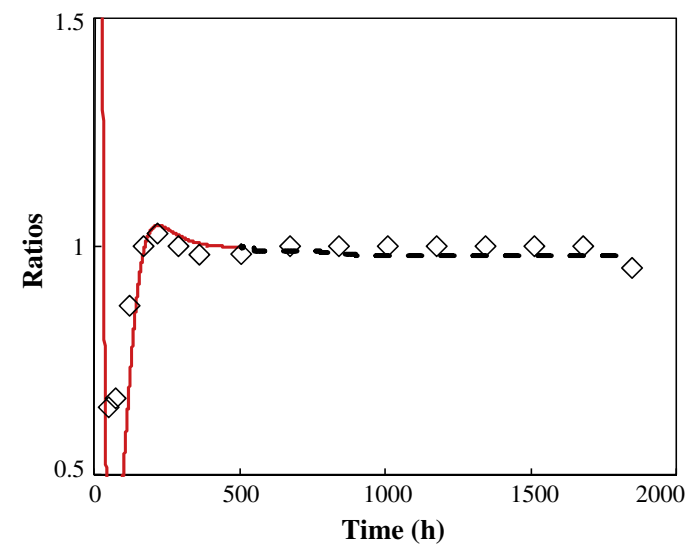

Fig. 3. Ratios of albite dissolution rates vs. sanidine precipitation rates when expressed in unit of $\mathrm{mol} \mathrm{s}^{-1} \mathrm{kgw}^{-1}$. Symbols denote experimental data; lines denote the results of numerical reaction path model simulation. Here and thereafter, the dotted line shows portion of $672-1848 \mathrm{~h}$.

tion $r_{\mathrm{Ab}}$ approximately, although not exactly (see below), were equal to the rates of sanidine precipitation $r_{\text {San }}$ on a $\mathrm{mol} \mathrm{s}^{-1} \mathrm{kgw}^{-1}$ basis (Fig. 3),

$\left|r_{\mathrm{Ab}}\right| \approx\left|r_{\mathrm{San}}\right|$

Note that discrete sanidine crystals were formed on albite surfaces or dissolution cavities in the experiments (Alekseyev et al., 1997). Therefore, the dissolution-precipitation process at $300{ }^{\circ} \mathrm{C}$ is fundamentally different from that at higher temperature (e.g., $600^{\circ} \mathrm{C}$ ), during which isomorphous replacement or "ion-exchange" reactions occurred (Putnis, 2002; Labotka et al., 2004).

Significant amounts of albite were dissolved from $672 \mathrm{~h}$ to $1848\left(\sim 5.8 \times 10^{-3} \mathrm{~mol} \mathrm{kgw}^{-1}\right.$ at $672 \mathrm{~h}$, and $65 \%$ of that was dissolved at $1848 \mathrm{~h}$ ) so that we must account for the variation of reactive surface areas associated with the change of albite mass. The parameters in Eq. (5) $k_{1}, m_{1}$, and $n_{1}$ for albite had already been fitted from the congruent dissolution data $(0$ $7 \mathrm{~h}$ ). However, the parameters for the second term in Eq. (5), $m_{2}$ and $k_{2}$, could not be determined using the Alek97 data at the congruent stage, in which dissolution occurred relatively far from equilibrium and therefore the first term of Eq. (5) dominated dissolution rates. The dissolution rates during $672-1848 \mathrm{~h}$ were mainly affected by reactive surface areas and also slightly by the second term of Eq. (5). We included the second term by assuming that the ratio of $k_{1} /$ $k_{2}=56.67$ and $m_{2}=1.17$ are the same as those of Hellmann and Tisserand (2006). However, the effects of including the second term in Eq. (5) are small in our study and the conclusions below are not affected by this assumption. With these parameters, we can calculate the ratio between the experimental rates $r_{\mathrm{Ab}}^{\mathrm{San}}$ and the rates computed from Eq. (5):

$r_{\mathrm{Ab}}^{\exp } / r^{*}$

where

$r^{*}=S_{\mathrm{Ab}}^{\mathrm{o}}\left\{k_{1}\left[1-\exp \left(-n_{1} g^{m 1}\right)\right]+k_{2}\left[1-\exp (-g)^{m 2}\right]\right\}$

and $S_{\mathrm{Ab}}^{\mathrm{o}}\left(\mathrm{m}^{2} \mathrm{kgw}^{-1}\right)$ is the initial surface area in the reactor for the time period of interest.
The ratios so calculated from Eq. (10) represent changes of reactive surface areas if all the fitting parameters are constant throughout the experiment and all additional factors not accounted in Eq. (11) are negligible for the period 672-1848 h (e.g., Al inhibition). Apparently, the calculated values of $r^{*}$ depend on the $k_{2}$ and $m_{2}$ values that are used. Use of Burch's $k_{1} / k_{2}$ and $m_{2}$, for example, would produce a different set of $r^{*}$ values. However, for the Alek97 experiments, the first term in Eq. (11) is dominant, even during $672-1848 \mathrm{~h}$.

It turned out that a decrease of the reactive surface area by a factor of 2.4 from 672 to $1828 \mathrm{~h}$ was necessary and the temporal evolution of the reactive surface areas can be approximated by an expression of $\left(N^{t} / N_{672 h}^{o}\right)^{2 / 3}$ for $t=672-1848 \mathrm{~h}$, which is not the best fit, but suits the principle of parsimony. The best fit was obtained with $\left(N^{t} / N_{672}^{\mathrm{o}}\right)^{0.8}$. As indicated previously, this $P$ value of $\sim 2 / 3$ may indicate that albite dissolution rates were approximately equal on all faces, and the shape of albite grains did not change during the dissolution.

To fit the sanidine precipitation rate data, we used the classic Burton-Cabrera-Frank (BCF) theory for crystal growth (Burton et al., 1951),

$r_{\mathrm{San}} / S_{\mathrm{San}}=-k\left(e^{\frac{\Delta G_{\mathrm{r}}}{R T}}-1\right)^{2}$

where all symbols are as presented before. The negative sign ensures proper accounting during the simulation.

As mentioned in Section 2, the reactive surface areas for the precipitating solids are difficult to estimate and the experimental data really defined the effective rate constant $k^{*}$. The temporal evolution of $k^{*}$ can be evaluated from the equation,

$k^{*}=k \times S_{\mathrm{San}}=-r_{\mathrm{San}} /\left(e^{\frac{\Delta G_{\mathrm{r}, \mathrm{San}}}{R T}}-1\right)^{2}$

where $\Delta G_{\mathrm{r} \text {,San }}$ was calculated according to $\mathrm{Zhu}$ and $\mathrm{Lu}$ (2009). The calculated $k^{*}$ values correlate linearly with $\left(N_{\text {San }}^{t}\right)^{0.5}$ (Fig. 4). This correlation cannot be used to derive the reactive surface area of sanidine, but numerically, is suf-

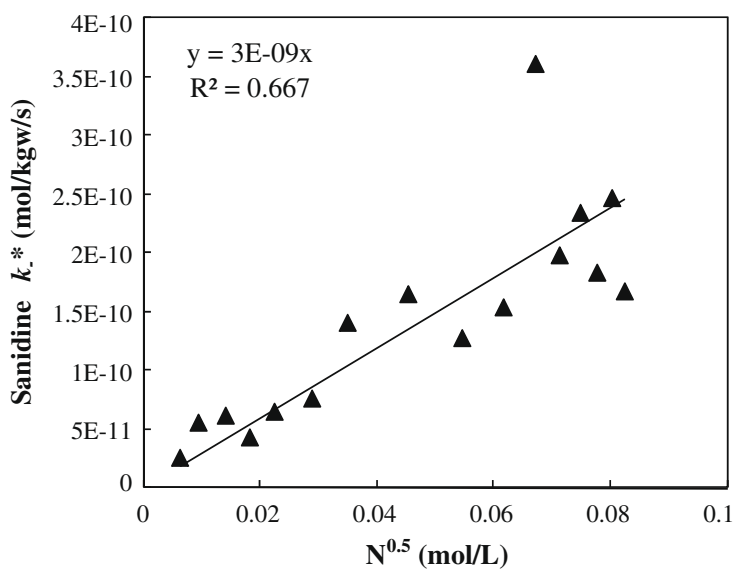

Fig. 4. Correlation between experimental effective rate constants $\left(k^{*}=k \times S\right)$ and the amount of sanidine precipitated. Both quantities were estimated. 
ficient to model the change in dissolution rate using the rate law,

$r_{\mathrm{San}}=-k^{\prime}\left(N_{\mathrm{San}}^{t}\right)^{0.5}\left(e^{\frac{\Delta G_{\mathrm{r}}}{R T}}-1\right)^{2}$

with a $k^{\prime}$ value of $3 \times 10^{-9} \mathrm{~mol} \mathrm{~m}^{-2} \mathrm{~s}^{-1}$.

In the simulation, the starting point was the experimental concentrations of $\mathrm{Na}, \mathrm{Si}, \mathrm{Al}$ and the estimated $N_{\mathrm{San}}$ at $672 \mathrm{~h}$ (these were batch experiments and each batch was not connected). The simulation results matched well with the experimental data. The good fit is demonstrated by the $\mathrm{Na}, \mathrm{Al}, \mathrm{Si}$ concentrations (Fig. 2), the Si:Al and $\mathrm{Si}: \mathrm{Na}$ ratios (Figs. 5 and 6), albite dissolution and sanidine precipitation rates (Fig. 7a and b), the saturation indices (Fig. 8), ratios of $r_{\mathrm{Ab}} / r_{\mathrm{San}}$ (Fig. 3), and the mass of albite and sanidine remaining in the batch reactors at the end of the experimental runs (Fig. 9).

The overall dissolution-precipitation reaction is,
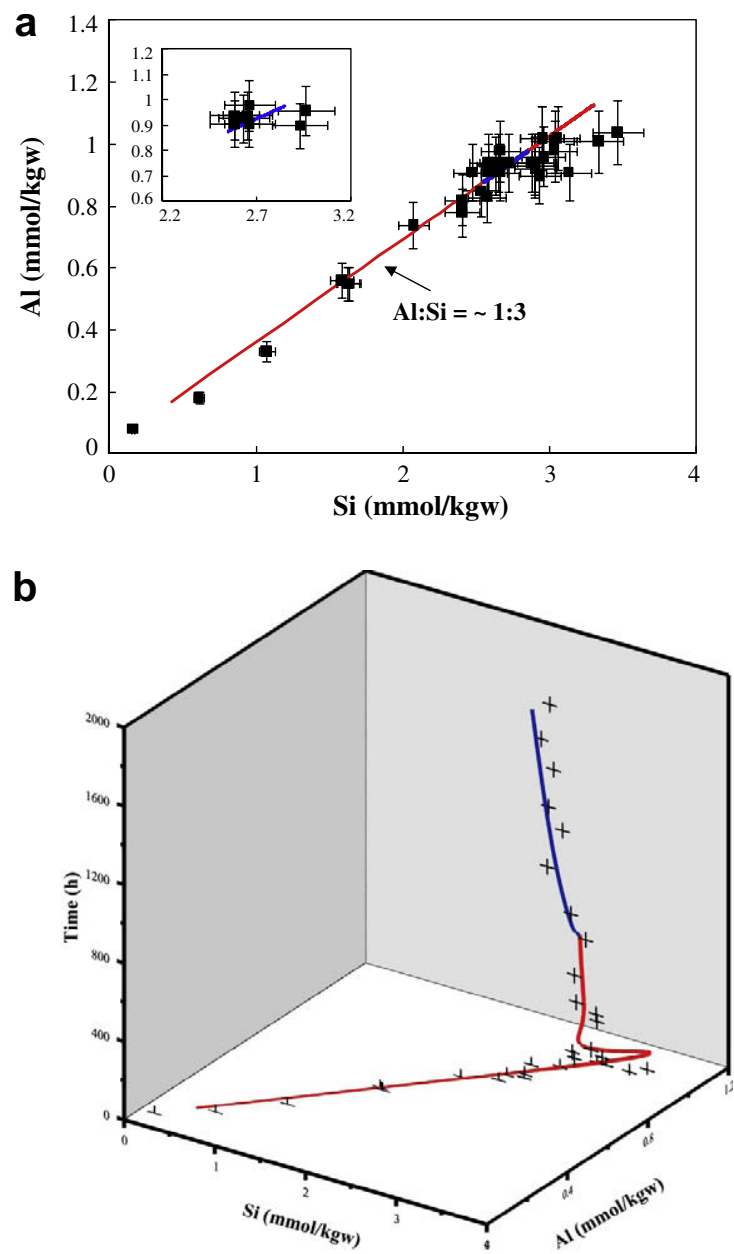

Fig. 5. Proportions of $\mathrm{Al}$ and $\mathrm{Si}$ concentrations over time. Symbols denote experimental data (Alek97); lines results from numerical reaction path model simulation. (a) Inset shows the simulation results during $672-1848 \mathrm{~h}$. (b) 3D diagram with time as the third axis to illustrate the temporal evolution. Stoichiometric dissolution of albite and sanidine precipitation would result in $\mathrm{Al}: \mathrm{Si} \approx 1: 3$, which coincide with the model simulation line.

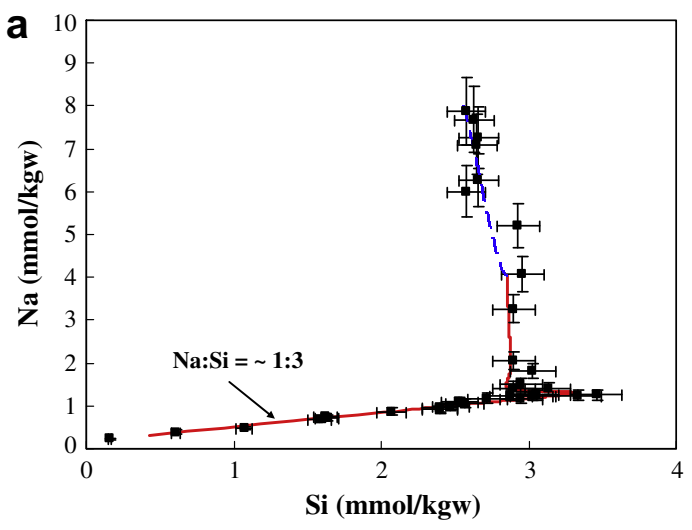

b

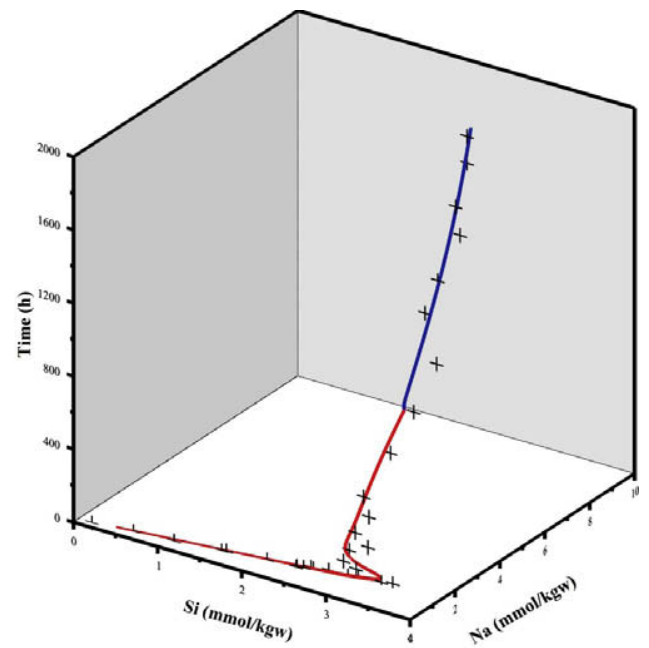

Fig. 6. Proportions of $\mathrm{Si}$ and $\mathrm{Na}$ concentrations over time. Symbols denote experimental data (Alek97); lines result from numerical reaction path model simulation. Stoichiometric and congruent dissolution of albite would result in $\mathrm{Na}: \mathrm{Si}=1: 3$. The experimental $\mathrm{Na} / \mathrm{Si}$ ratios fall on the $\mathrm{Na}: \mathrm{Si}=1: 3$ line for the first $7 \mathrm{~h}$, then significantly deviated from 1:3 when sanidine started to precipitate.

$\mathrm{NaAlSi}_{3} \mathrm{O}_{8}+\mathrm{K}^{+} \rightarrow \mathrm{KAlSi}_{3} \mathrm{O}_{8}+\mathrm{Na}^{+}$

As albite is dissolved, $\mathrm{Na}^{+}$concentrations increased while the $\mathrm{Al}^{3+}$ and $\mathrm{Si}$ concentrations remained almost constant (Fig. 2) and the Al:Si ratios are almost 1:3 (Fig. 5). Because $\mathrm{Na}^{+}$increased, Saturation index (SI) for albite increased with time (Fig. 8) and hence the slight decrease of $r_{\mathrm{Ab}}$ with time (Fig. 7a). Sanidine rates also decreased with time (Fig. 7b).

Of particular note is the simulated $r-\Delta G_{\mathrm{r}}$. Alekseyev et al. (1997) discussed the peculiar experimental data of the incongruent stage for both albite and sanidine. We will discuss them later in more detail, but here we focus on the reactions that occurred between 672 and $1848 \mathrm{~h}$. The simulated $r-\Delta G_{\mathrm{r}}$ matched well with experimental data between 672 and $1848 \mathrm{~h}$ (Fig. 10a). The decrease of $r_{\mathrm{Ab}}$ was due to both a slight increase of $\Delta G_{\mathrm{r}, \mathrm{Ab}}$ and a decrease of $S_{\mathrm{Ab}}$. For sanidine, the simulation also matched well with experimental sanidine rates (Fig. 7b). Note that Fig. 10a and b are different from Fig. $1 \mathrm{a}$ and $\mathrm{b}$ because the rates are ex- 

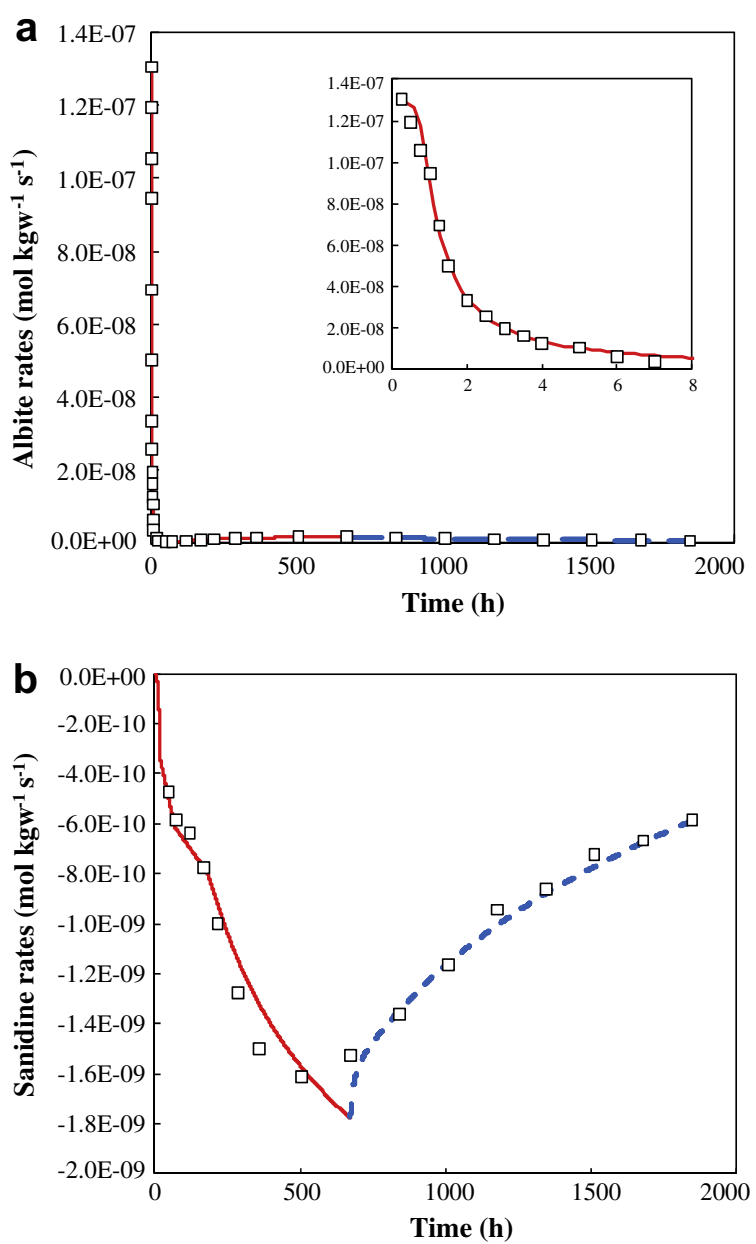

Fig. 7. Albite dissolution (a) and sanidine precipitation (b) rates over time. Symbols denote experimental data (Alek97); lines result from numerical reaction path model simulation. Note that the unit of the rates is expressed in $\mathrm{mol} \mathrm{s}^{-1} \mathrm{kgw}^{-1}$. An empirical function was used in order to take into account changes in surface reactivity with time (see text). Rates are a function of both $S$ and $\Delta G_{\mathrm{r}}$.

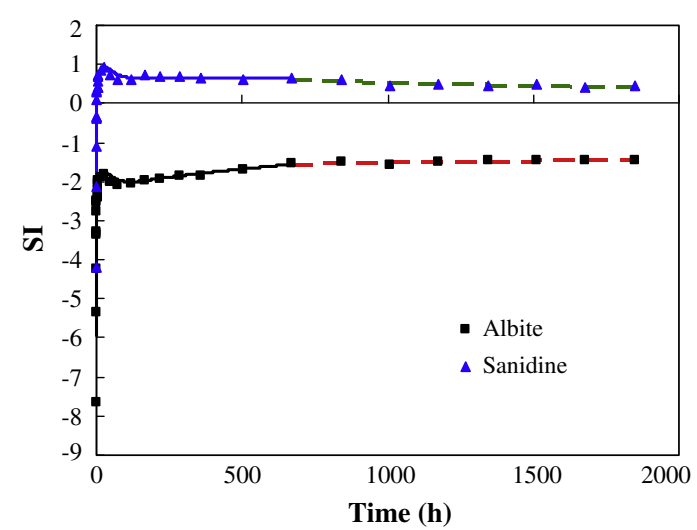

Fig. 8. Saturation indices (SI) over time. Symbols represent SI calculated from speciation-solubility modeling for samples independently from each other (as snapshots) (Zhu and Lu, 2009). Lines from reaction path modeling that simulate the processes.
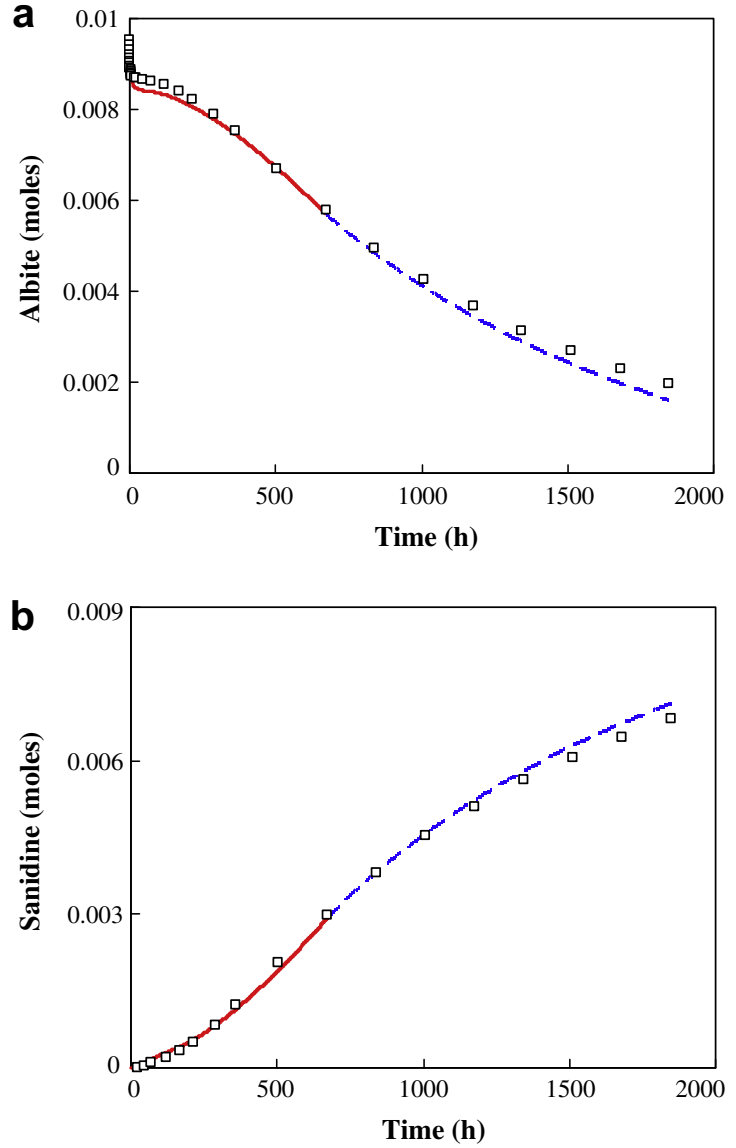

Fig. 9. Comparison of the mass of albite (a) and sanidine (b) in the reactor $\left(\mathrm{mol} \mathrm{kgw}^{-1}\right)$ predicted from the reaction path simulation (line) with rough estimation from rates and reaction intervals (symbols).

pressed as $\mathrm{mol} \mathrm{s}^{-1} \mathrm{kgw}^{-1}$ so that the rate changes are a function of both $\Delta G_{\mathrm{r}}$ and $S_{j}$. The agreement, therefore, indicates that the formulae for $S(t)$ as a function of moles of albite and sanidine and the BCF model of sanidine precipitation generated acceptable approximations.

The simulations based on these assumptions generated results that match the experimental data for the period $672-1848 \mathrm{~h}$. The most important result is a quasi-steady state in terms of $r_{\mathrm{Ab}} / r_{\mathrm{San}}$ ratios that are almost unity. This important conclusion is not related to more assumptions below, which are needed to simulate the experimental period 7-504 h.

\subsubsection{Albite incongruent dissolution with initiation of sanidine precipitation (7-504 h)}

The Alek97 experiments started with an aqueous solution that was undersaturated with respect to sanidine. The sanidine SI rose rapidly, becoming supersaturated at $1.5 \mathrm{~h}$ and reaching a maximum of $\sim 1.0$ at $24 \mathrm{~h}$ (Fig. 8). From that point on, the sanidine SI decreased linearly, approaching but not reaching zero. This SI temporary evolution is a typical result of competition between continued primary mineral dissolution and secondary mineral nucleation and growth (Fritz and Noguera, 2009). 

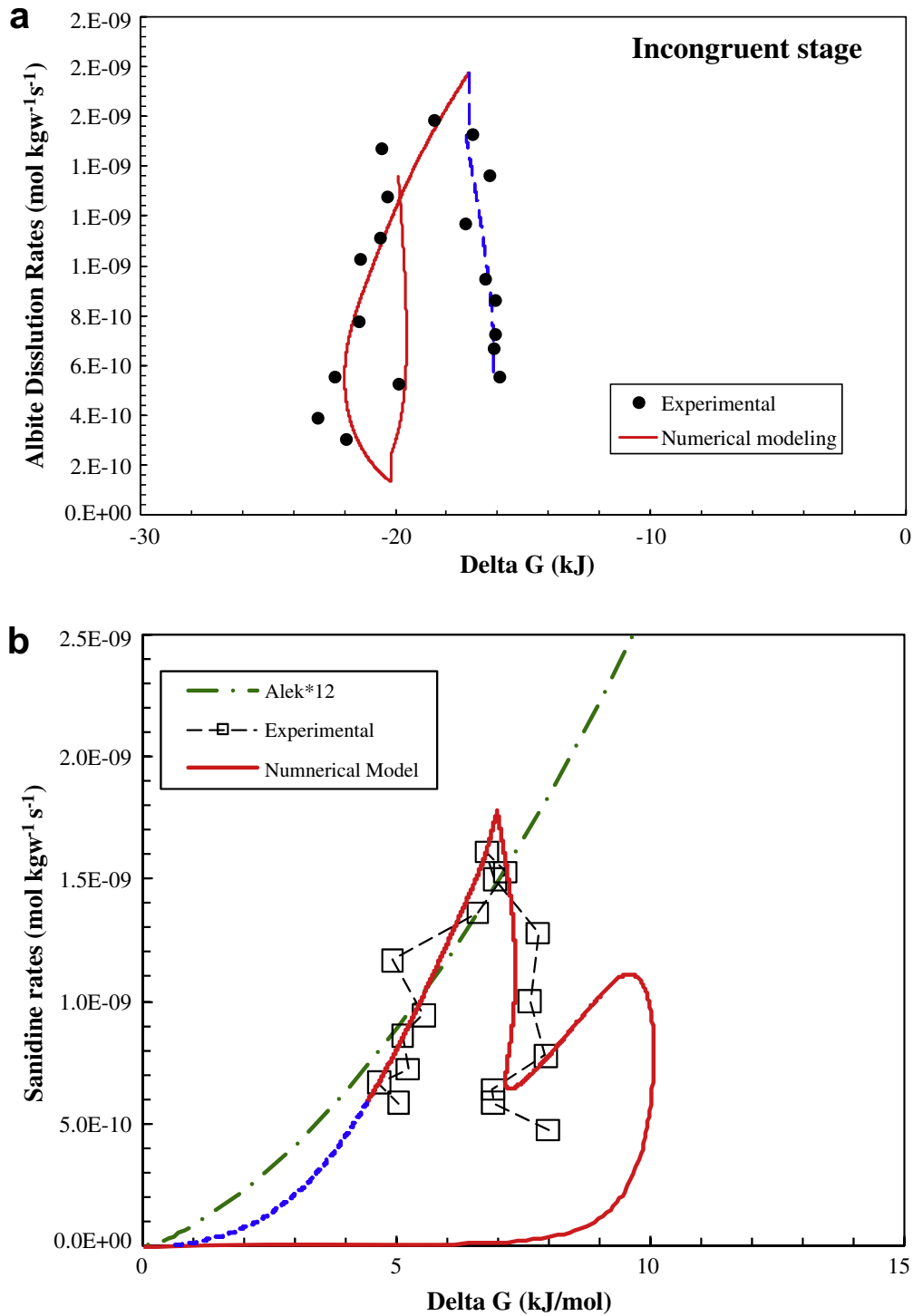

Fig. 10. Albite dissolution (a) and sanidine precipitation (b) rates (in $\mathrm{mol} \mathrm{s}^{-1} \mathrm{kgw}^{-1}$ ). Symbols denote experimental data (Alek97) and lines represent reaction path simulation. An empirical function was used in order to take into account changes in surface reactivity with time (see text). Labels besides symbols indicate hours of reaction. Dotted line shows simulation extended to $4445 \mathrm{~h}$.

The beginning of sanidine nucleation was marked by a perturbation of $\mathrm{Al}$ and $\mathrm{Si}$ concentrations (Fig. 2b and c) and also SI of albite, which first increased rapidly until reaching a maximum at $24 \mathrm{~h}$, then decreased from 24 to $72 \mathrm{~h}$, and finally increased linearly from 72 to $1848 \mathrm{~h}$ (Fig. 8). Because of the similarity of the albite and sanidine structures, sanidine nucleation is expected to be on albite surface sites. It is apparent that nucleation of sanidine on albite surfaces caused a dramatic decrease of the albite dissolution rate (Fig. 7a). $r_{\mathrm{Ab}}$ decreased monotonically during the first $48 \mathrm{~h}$, even though there is an albite maximum in SI during this period (7-48 h, Fig. 8). This observation indicates that the $r_{\mathrm{Ab}}$ decrease was not merely a function of $\Delta G_{\mathrm{r}, \mathrm{Ab}}$. It appears that changes of reactive surface area must also have contributed.

Such reduction of the "reactive surface area" cannot be accounted for by the reduction in the physical surface areas (be geometric or BET), but only by the blocking of the reactive surface sites on albite, due to the presence of an inhibitor or due to surface coating. It has been shown in several studies that dissolution rates of feldspar are retarded in the presence of Al (Gautier et al., 1994; Oelkers et al., 1994; Oelkers, 2001). However, the experimental data of Alek97 show that $\mathrm{Al}$ concentrations are 1.02, 1.01, 1.04, and $1.01 \mathrm{mM}$ at 7, 16, 24, and $48 \mathrm{~h}$, respectively. As the drastic reduction of $r_{\mathrm{Ab}}$ coincided with almost constant $\mathrm{Al}$ concentrations for 7-48 h (Fig. 11), Al inhibition alone cannot explain the reduction in albite dissolution rates here. We suggest that the reduction in $r_{\mathrm{Ab}}$ was due to the nucleation of sanidine on the albite surface. From 7 to $48 \mathrm{~h}$, the amount of sanidine increased from 0 to $0.04 \mathrm{mmol} \mathrm{kgw}^{-1}$. As the amount of albite $\left(8.7 \mathrm{mmol} \mathrm{kgw}^{-1}\right)$ was much higher, one can argue that the amount of growing sanidine is not sufficient to fully cover the surface of albite. However, 


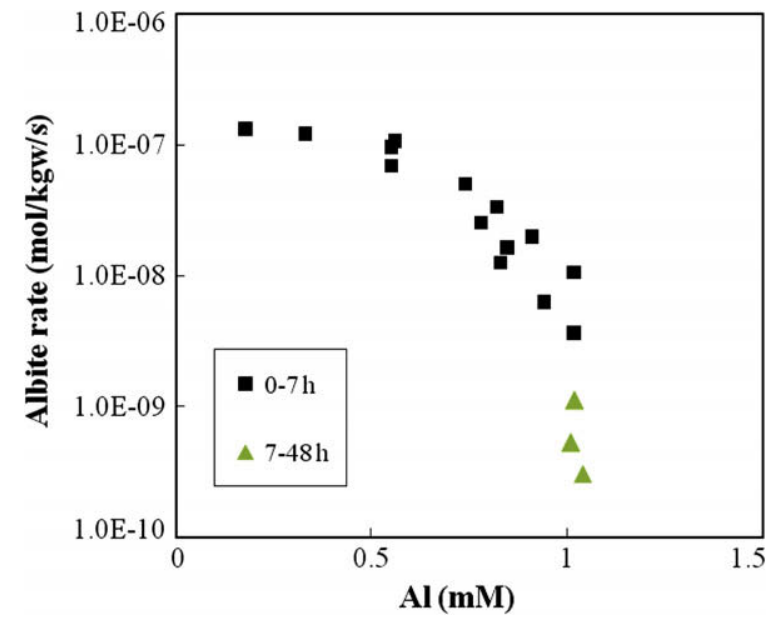

Fig. 11. Rate of dissolution of albite as a function of dissolved $\mathrm{Al}$ concentrations. Rates are expressed in $\mathrm{mol} \mathrm{s}^{-1} \mathrm{kgw}^{-1}$.

mineral dissolution (as well as crystal growth) mainly occurs on the reactive surface sites that are provided by kinks, and a full blockage of these sites can still be attained with relatively small amounts of coating. For example, it has been reported that only a few percent of a crystal surface needs to be covered with an inhibitor to achieve total blockage of the crystal growth process (Liu and Nancollas, 1975; Weijnen and Van Rosmalen, 1986; Hoch et al., 2000). It is expected that sanidine nucleation would mainly occur at or near the sites were albite dissolution occurred, as (1) these sites may provide a template for nucleation and (2) the oversaturation may be somewhat higher near the dissolving sites due to the local supply of $\mathrm{Al}$ and $\mathrm{Si}$. Indeed, Alek97 observed that crystals of sanidine were nucleated mainly on the walls of dissolution cavities in albite (see Fig. 4c of Alek97).

However, even though the experimental evidence pointed out nucleation on albite surface as the probable cause for the reduction of albite reactivity, modeling this process quantitatively is still impossible at the present time (see review by Fritz and Noguera, 2009). An ad hoc approach must be used instead. If we assume that the first term in Eq. (5) has adequately accounted for the $r-\Delta G_{\mathrm{r}}$ effects (in fact the second term as described in the previous section has little effect here because of the distance from equilibrium), we can compute the ratios between rates predicted from Eq. (5) with the initial surface area $S_{j}^{o}$ and the experimental rates. The ratios can be regarded as the correction factors $Y\left(Y=S_{j}^{\mathrm{o}} k_{1}\left[1-\exp \left(-n_{1} g^{m 1}\right)\right] / r^{\exp }\right) . Y$ needs to be $4 \times, 6 \times, 20 \times$ smaller at 16,24 , and $48 \mathrm{~h}$, respectively. Apparently, during this period of sanidine nucleation, the change in the reactivity of the albite cannot be described by the formula $\left(N / N^{\mathrm{o}}\right)^{0.67}$ that was used for $672-1848 \mathrm{~h}$ in Section 3.2, which here can only provide a correction factor of 1.05. It seems that the decrease in albite reactivity from 7 to $48 \mathrm{~h}$ is independent of the change in albite concentration. To describe this change in reactivity, we used a time dependent $Y$ function. The regression of $Y$ generated $Y=e^{0.0661 t}$ where $Y$ appears in the denominator in Eq. (5) and $t$ is the reaction time in hours. With this empirical fitting, the experimental data of the first $48 \mathrm{~h}$ were approximately reproduced.

Alek97 noted that, for the incongruent dissolution stage, the $r_{\mathrm{Ab}}-\Delta G_{\mathrm{r}, \mathrm{Ab}}$ relationships were erratic, in a horseshoe shape, as shown in Fig. 10a. At first glance, this experimental observation defies the TST, but these rates are not normalized to the reactive surface area. This horseshoe shape could be explained by the coalescence of sanidine nucleus and particles. At this stage (48-504 h), the degree of oversaturation with respect to sanidine is much lower than that during the peak of the nucleation stage (around $16 \mathrm{~h}$ ). Numerical modeling of simple precipitation and growth of clay particles in model systems show that the small particles initially created are subsequently destabilized and resorbed. Only some classes of particles survive and grow (Fritz and Noguera, 2009). This process appears to explain the increase of reactive surface areas and albite dissolution rates from 48 to $\sim 500 \mathrm{~h}$ (Fig. 7a) while $r_{\mathrm{Ab}}$ apparently correlates positively with the increase of $\Delta G_{\mathrm{r}, \mathrm{Ab}}$ (Fig. 10a). Currently, we cannot predict the increase in albite reactive surface area, and therefore we need to employ empirical functions that would describe it. The $Y$ function $Y=4600.5 t^{-1.202}$ for 48-504 h helped the match between simulated and experimental values. The simulation also matched well with the non trivial $r_{\mathrm{Ab}}-\Delta G_{\mathrm{r}, \mathrm{Ab}}$ relationship (Fig. 10a).

\subsubsection{Sanidine precipitation $(7-672 h)$}

The precipitation of sanidine $7-672 \mathrm{~h}$ was constrained by experimental data $r_{\text {San }}$, and $\mathrm{Na}: \mathrm{Si}$ ratios (Figs. 6 and 7b). $r_{\text {San }}$ increased with time until about $504 \mathrm{~h}$ (Fig. 7b). This monotonic increase coincided with an increase, a decrease, and an increase again of sanidine SI (Fig. 8). The sanidine $r-\Delta G_{\mathrm{r}}$ relationship is also erratic, with an increase of $r_{\text {San }}$ coinciding with a decrease of $\Delta G_{\mathrm{r}, \text { San }}$ during 7-504 $\mathrm{h}$ and forming a horseshoe shape for the entire experimental period (Fig. 10b). However, close inspection shows that $r-\Delta G_{\mathrm{r}}$ is not randomly distributed, but follows a strict chronological order of increasing rates with increasing time from 48 to $504 \mathrm{~h}$ (Fig. 10b).

The BCF theory-based approach, combined with an empirical formula for reactive surface area increase (Eq. (14)), appears to account well for the competing effects of $\Delta G_{\mathrm{r}}$ and $S_{\mathrm{San}}$. Rates increased to $504 \mathrm{~h}$ due to the rapid increase of reactive surface areas despite a slight decrease of $\Delta G_{\mathrm{r}, \mathrm{San}}$. After $504 \mathrm{~h}$, the decrease of $\Delta G_{\mathrm{r}, \mathrm{San}}$ offset the small increase of $S_{\mathrm{San}}$ and the overall precipitation rates declined. The decrease of $\Delta G_{\mathrm{r}, \text { San }}$ was caused by the slowdown of albite dissolution. The reaction path model was able to simulate the horse shoe shaped $r-\Delta G_{\mathrm{r}}$ without excess fitting. Note that the wiggles around 24 and $120 \mathrm{~h}$ in Fig. $10 \mathrm{~b}$ are due to changes of SI. The simulation was able to catch all these variations.

\subsubsection{Simulation of the entire experiment period (0-1848 h) and beyond}

When all the time segments discussed above were put together in a model and the entire period of the experiment was simulated at once, the results matched well with the experimental data (Figs. 2, 3, 5-10, and 12). It should be noted that $\Delta G_{\mathrm{r}, \mathrm{Ab}}$ never reached values $>-16 \mathrm{~kJ} \mathrm{~mol}^{-1}$ 


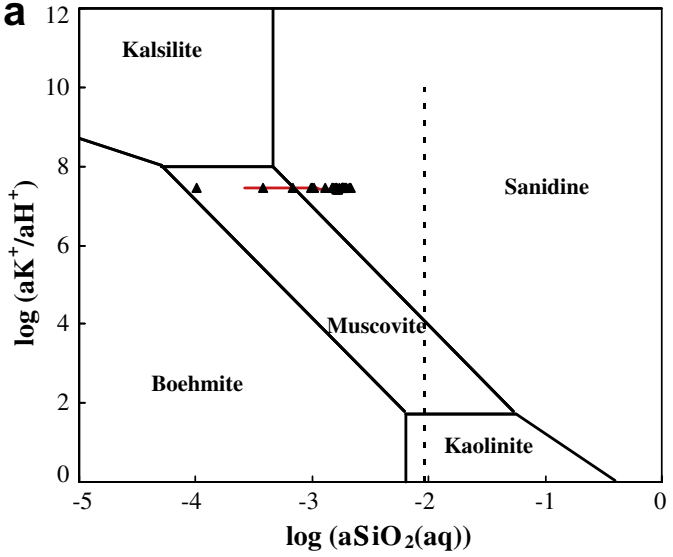

b

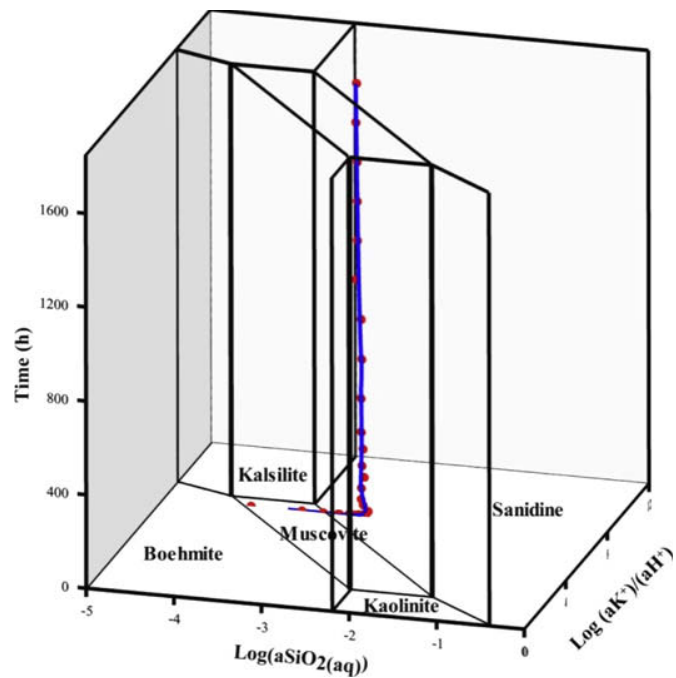

Fig. 12. (a) Activity diagram in the $\mathrm{K}_{2} \mathrm{O}-\mathrm{Al}_{2} \mathrm{O}-\mathrm{SiO}_{2}-\mathrm{H}_{2} \mathrm{O}-\left(\mathrm{CO}_{2}\right)-$ $\mathrm{HCl}$ system at $300{ }^{\circ} \mathrm{C}$ and 88 bars for albite dissolution. The dashed line is quartz saturation. Symbols denote experimental results, and the solid line the reaction path simulation results. (b) Shows the evolution of reaction path as a function of time.

(Fig. 10a). The experiments experienced a period when sanidine precipitation proceeded faster than albite dissolution as sanidine was nucleated (Fig. 3). After $\sim 300 \mathrm{~h}$, a quasisteady state was reached where $\left|r_{\mathrm{Ab}}\right| /\left|r_{\text {San }}\right|$ is close to unity (Fig. 3). The simulation shows that the ratio was stabilized at $\sim 0.98$. It should be pointed out that a poor match for sanidine simulations in the early stage of our trial and error simulations would not grossly upset the simulated $\left|r_{\mathrm{Ab}}\right|$ $\left|r_{\text {San }}\right|$ in a later time. The system appears to revert to a quasi-steady state regardless.

We also performed predictive simulations, extending to $4445 \mathrm{~h}$, beyond the experimental duration of $1848 \mathrm{~h}$. All albite was dissolved at ca. $3650 \mathrm{~h}$. Sanidine continued to precipitate until equilibrium was reached at ca. $4170 \mathrm{~h}$ (Fig. 13a). The ratios of $\left|r_{\mathrm{Ab}}\right| /\left|r_{\mathrm{San}}\right|$ remain at 0.98 (Fig. 13b). Note that due to the coupling between albite dissolution and sanidine precipitation, albite never reached equilibrium with the aqueous solution, but continued to dissolve at almost the same degree of undersaturation $\left(\Delta G_{\mathrm{r}, \mathrm{Ab}} \approx-16 \mathrm{~kJ} \mathrm{~mol}^{-1}\right)$.
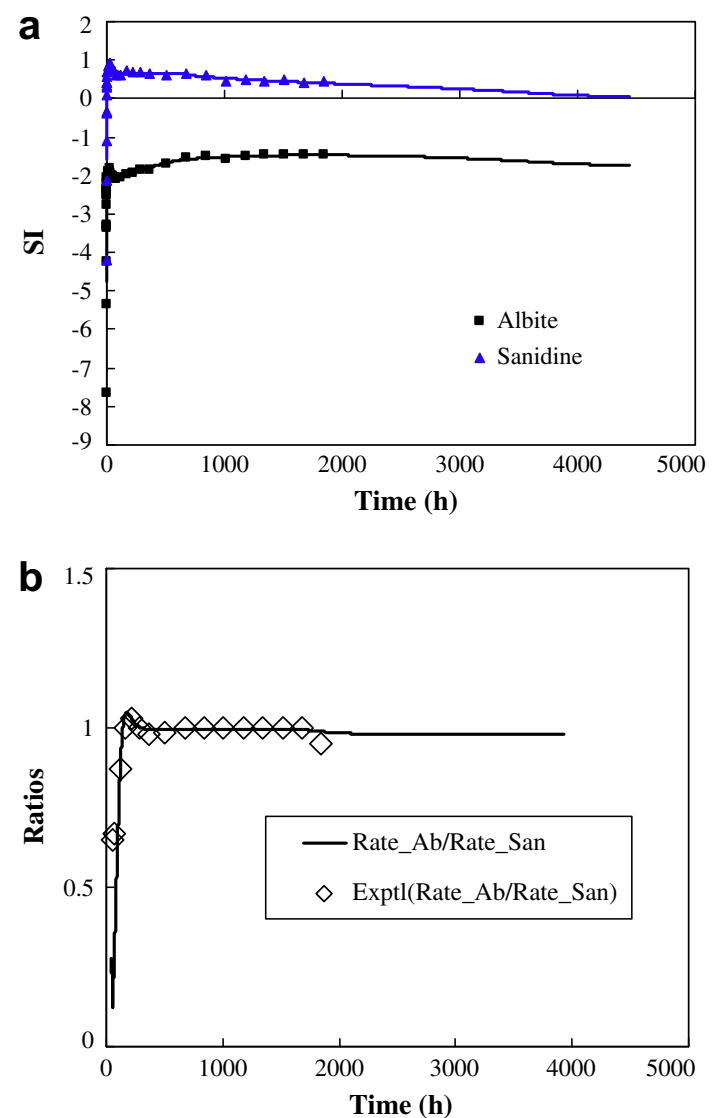

Fig. 13. Predicted continued reactions in the batch reactor beyond experimental time of $1848 \mathrm{~h}$ following the reaction path model. (a) saturation indices over time; (b) ratios of albite dissolution rates vs. sanidine precipitation rates. Albite was dissolved at ca. $3650 \mathrm{~h}$. Sanidine continued to precipitate until reaching equilibrium at ca. $4170 \mathrm{~h}$.

\subsection{Feldspar hydrolysis batch experiments at $200{ }^{\circ} \mathrm{C}$ and 300 bars}

The two feldspar hydrolysis batch experiments were described in detail in Zhu and $\mathrm{Lu}$ (2009). The batch experiments dissolved alkali feldspar $\left(\mathrm{Na}_{0.95} \mathrm{Ca}_{0.04} \mathrm{~K}_{0.01} \mathrm{Al}_{1.04-}\right.$ $\mathrm{Si}_{2.96} \mathrm{O}_{8}$ and $\mathrm{K}_{0.85} \mathrm{Na}_{0.15} \mathrm{Al}_{1.04} \mathrm{Si}_{2.97} \mathrm{O}_{8}$ laminae) in $\sim 0.20 \mathrm{M}$ $\mathrm{KCl}-\mathrm{HCl}$ solution with $50 \mathrm{mM} \mathrm{CO} 2$ for 5 and 27 days. The experiments were conducted at $200{ }^{\circ} \mathrm{C}$ and 300 bars. The precipitates were identified as mainly boehmite and possibly trace of muscovite after five days. The retrieved solids from the 27 day batch show much more coverage of secondary minerals on feldspar grains than those after 5 days, but XRD analysis was not successful. The approximately 1:3 Na:Si ratio in the aqueous solution indicates stoichiometric dissolution of albite. The amount of muscovite or microcline precipitation must be negligible.

To model albite dissolution, we used Eq. (5) and a far from equilibrium $k_{1}$ derived from Hellmann et al. (1990)'s albite dissolution experiment at $225^{\circ} \mathrm{C}(\mathrm{pH} 3.66)$ with an activation energy $E_{\mathrm{a}}$ of $50 \mathrm{~kJ} \mathrm{~mol}^{-1}$. For the exponent parameters and $k_{1} / k_{2}$ ratio in Eq. (5), we adopted the values from Hellmann and Tisserand (2006). Only a small percentage of albite was dissolved in the experiment so that we 
assumed that the reactive surface areas of albite remained constant during the experiments. The measured BET SA $0.132 \mathrm{~m}^{2} \mathrm{~g}^{-1}$ was used for the reactive surface area.

For boehmite precipitation, we essentially followed Bénézeth et al. (2008) and used the rate law,

$r_{\mathrm{Bhm}}=-k^{*}\left(H^{+}\right)^{1.7}\left(e^{\frac{\Delta G_{\mathrm{r}}}{R T}}-1\right)$

Bénézeth et al. (2008) conducted boehmite precipitation experiments for $\mathrm{pH} 6-9$ at $100.3^{\circ} \mathrm{C}$. They found that the TST $f\left(\Delta G_{\mathrm{r}}\right)$ function fit to their data and the precipitation rate is a function of $\mathrm{pH}$. Boehmite precipitation in our experiments occurred in the $\mathrm{pH}$ range of 4.5-5.1, slightly more acidic than the experimental conditions of Bénézeth et al. (2008). Nagy (1995) documented V-shaped pH dependence of aluminum oxyhydroxides dissolution rates and proposed an exponent of 1.7 for hydrogen concentrations for acidic solutions, which we adopted.

In the reaction path model, the only fitted term in Eq. (15) was the effective rate constant $k_{\mathrm{Bhm}}^{*}$, which was assumed to be constant here because the reactive surface areas for boehmite could not be assessed independently. The first aqueous sample was taken after $24 \mathrm{~h}$. Therefore, the experimental data probably represent the stage where the initial nucleation of boehmite was already passed.

Such a simplistic model matched well with the solution chemistry evolution in the first $312 \mathrm{~h}$ of the experiments (Fig. 14). Si and $\mathrm{Na}$ concentrations increased rapidly (0$312 \mathrm{~h}$ ) as albite dissolved first starting from the condition of far from equilibrium, but the increase decelerated due to the $f\left(\Delta G_{\mathrm{r}}\right)$ term in the rate law. The $\mathrm{Al}$ concentrations appear to reach a quasi-steady state as a result of the competition between albite dissolution and boehmite precipitation. The $\mathrm{pH}$ increased because boehmite precipitation consumes $\mathrm{H}^{+}$. Note that the dominant $\mathrm{Al}$ species is $\mathrm{Al}(\mathrm{OH})_{4}{ }^{-}$in this experiment (Zhu and Lu, 2009). The predicted SI over time matched well with speciation-solubility calculations for both primary mineral (albite) and secondary mineral (boehmite) (Fig. 15).

Essentially, the reaction path model simulated albite dissolution,

$\mathrm{NaAlSi}_{3} \mathrm{O}_{8}+2 \mathrm{H}_{2} \mathrm{O} \rightarrow \mathrm{Na}^{+}+\mathrm{Al}(\mathrm{OH})_{4}{ }^{-}+3 \mathrm{SiO}_{2(\mathrm{aq})}$

and boehmite precipitation,

$\mathrm{Al}(\mathrm{OH})_{4}{ }^{-}+\mathrm{H}^{+} \rightarrow \mathrm{AlO}(\mathrm{OH})+2 \mathrm{H}_{2} \mathrm{O}$

The albite dissolution and boehmite precipitation reactions are closely coupled. Change of $k_{\mathrm{Bhm}}^{*}$ and hence the boehmite precipitation rate resulted in changes of albite dissolution rate and predicted $\mathrm{Si}$ and $\mathrm{Na}$ concentrations. In other words, the $k_{\mathrm{Bhm}}^{*}$ was constrained by both $\mathrm{Al}$ and $\mathrm{Si}-\mathrm{Na}-\mathrm{H}$ concentrations. The ratios of albite dissolution and boehmite precipitation rates are unity on a mol s${ }^{-1} \mathrm{kgw}^{-1}$ basis although the individual rates decreased rapidly as solutes accumulate in the solution (Fig. 16). The stoichiometric rate ratio is $1: 1$, reflecting the overall reaction,

$$
\begin{aligned}
\mathrm{NaAlSi}_{3} \mathrm{O}_{8}(\text { albite })+\mathrm{H}^{+} \rightarrow & \mathrm{AlO}(\mathrm{OH})(\text { boehmite }) \\
& +\mathrm{Na}^{+}+3 \mathrm{SiO}_{2(\mathrm{aq})}
\end{aligned}
$$

This result is significant and consistent with the conclusions in Section 3.1 and Ganor et al. (2007). Note that the above modeling results are largely predictive. No fitting parame- ters were used for albite. The only fitting parameter was $k_{\mathrm{Bhm}}^{*}$, which was constrained by the $\mathrm{Si}, \mathrm{Na}, \mathrm{Al}$, and $\mathrm{H}$ data. The assumption of a constant reactive surface area cannot be true as no boehmite seeds were used in the experiments and boehmite reactive surface areas have certainly grown. Another assumption was that the albite dissolution rate is
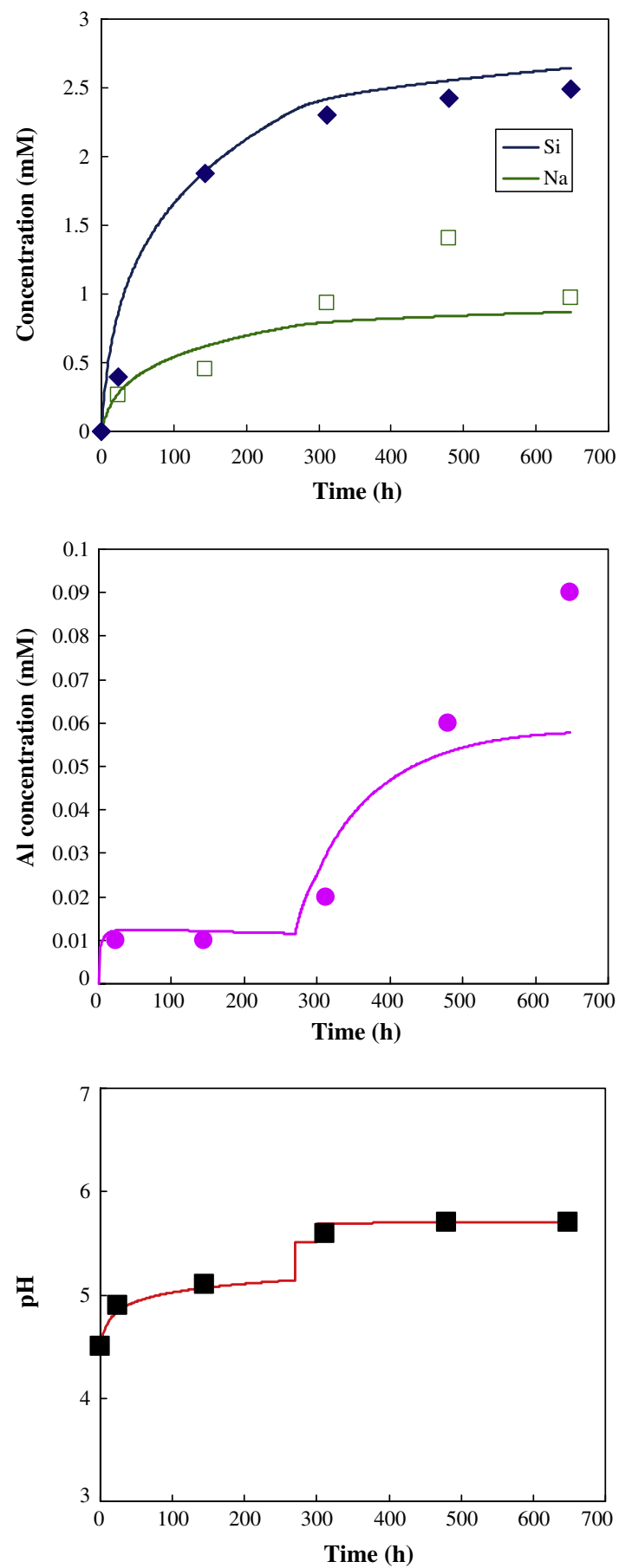

Fig. 14. Comparison of predicted solution chemistry from the reaction path model (lines) with experimental data (symbols) during the course of alkali feldspar dissolution batch experiments at $200{ }^{\circ} \mathrm{C}$ and 300 bars. The $\mathrm{pH}$ values in the simulation were adjusted to fit the experimental data. 


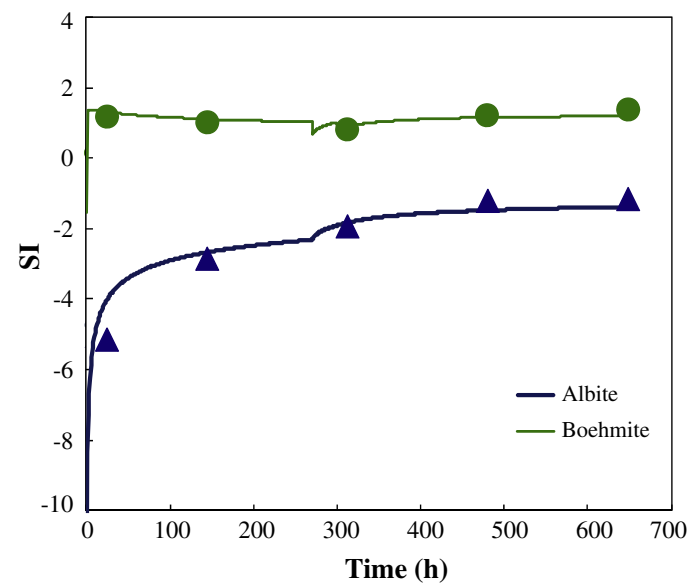

Fig. 15. Calculated change in albite and boehmite saturation indices evolution compared with data from solubility calculations (Zhu and Lu, 2009).

independent of $\mathrm{pH}$, which was not a large factor for the first $312 \mathrm{~h}$, but will artificially over-predict the albite dissolution rates for the late stage.

However, the above simple reaction path model can only match the $312-648 \mathrm{~h}$ experimental data by ad hoc adjustment of the $\mathrm{pH}$ in the model to experimental values (Figs. 14 17). Here the in situ $\mathrm{pH}$ values in the reactor were calculated from $\mathrm{pH}$ measured at room temperature and re-calculated to the experimental temperature via speciation-solubility modeling (Reed and Spycher, 1984; Zhu and Lu, 2009). While the values were calculated from modeling and these values cannot be verified independently, the model was applied consistently and hence the trend is probably reliable. We noted that measured $\mathrm{CO}_{2(\mathrm{aq})}$ concentrations decreased to $44 \mathrm{mM}$ from the starting concentrations of $50 \mathrm{mM}$ around $300 \mathrm{~h}$. However, modeling calculations show that possible degassing cannot account for the large increase of $\mathrm{pH}$ as observed.

We should mention that, with exception of $\mathrm{pH}$ after $312 \mathrm{~h}$, the experimental data constrain the rate laws. A change in the form of the rate law or its parameters would result in a mismatch with the experimental data. For example, if we had used a BCF rate law for boehmite precipitation instead but kept all other parameters the same in Eq. (15), the predicted $\mathrm{Al}$ concentrations after $312 \mathrm{~h}$ would be too low. The order of $\mathrm{H}^{+}$concentration in Eq. (15) was constrained by the $\mathrm{Al}$ concentration increase after $312 \mathrm{~h}$. A higher order would be a better fit. Different sets of exponents in Eq. (5) for albite dissolution would result in a mismatch with the experimental data as the curvature of $\mathrm{Si}$ and Na increase over time define the $f\left(\Delta G_{\mathrm{r}}\right)$ dependence of albite dissolution. Therefore, while the batch experimental data did not define a unique reaction path model, it was at least narrowed down to a limited sets of plausible models.

\section{DISCUSSIONS}

\subsection{The influence of $f\left(\Delta G_{\mathrm{r}}\right)$ and $S_{j}$ on the coupling of reactions}

Although the inter-dependence between dissolution and precipitation reactions has been discussed before in the lit-
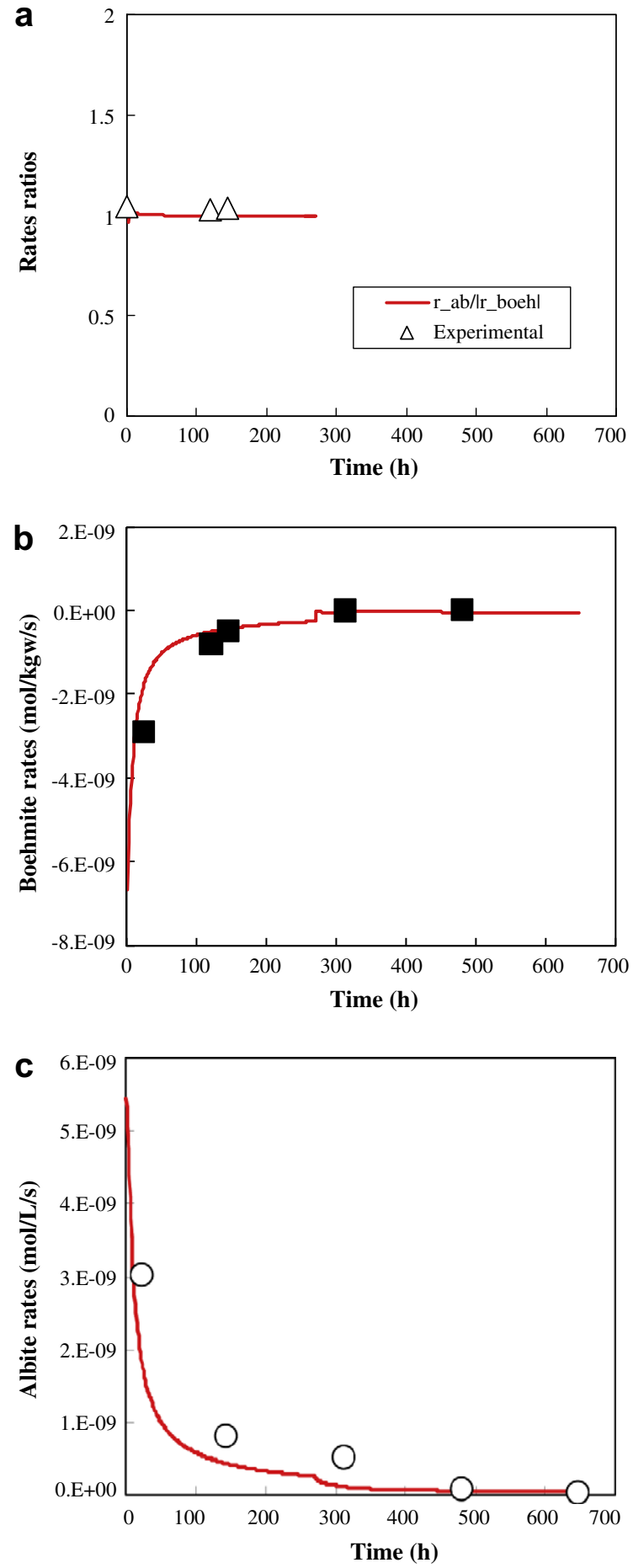

Fig. 16. (a) Simulated ratios of albite dissolution rates versus boehmite precipitation rates when expressed in unit of mol s${ }^{-1} \mathrm{kgw}^{-1}$ for the first $312 \mathrm{~h}$. (b) Boehmite precipitation rates over time. (c) Albite dissolution rates over time. Bulk albite dissolution rates in unit of $\mathrm{mol} \mathrm{kgw}^{-1} \mathrm{~s}^{-1}$ were estimated from the average release rates of $\mathrm{Na}$ and $\mathrm{Si}$ and boehmite precipitation rates from the balance on $\mathrm{Al}$.

erature (e.g., Alek97), the development of a numerical model allows us more freedom to explore this relationship 


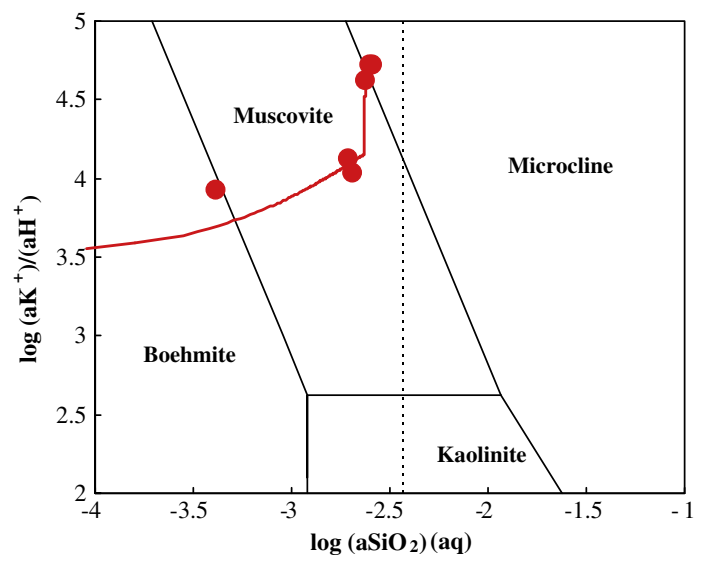

Fig. 17. Activity diagram in the $\mathrm{K}_{2} \mathrm{O}-\mathrm{Al}_{2} \mathrm{O}_{3}-\mathrm{SiO}_{2}-\mathrm{H}_{2} \mathrm{O}-\left(\mathrm{CO}_{2}\right)-$ $\mathrm{HCl}$ system at $200{ }^{\circ} \mathrm{C}$ and 300 bars. The symbols represent values calculated by $\mathrm{Zhu}$ and $\mathrm{Lu}$ (2009) from experimental data via speciation-solubility modeling. The line denotes to reaction path modeling prediction from this study.

quantitatively. Let's look at the simulation of Alek97 experiments discussed in Section 3. On the basis of mol s${ }^{-1} \mathrm{kgw}^{-1}$, we have $\left|r_{\mathrm{Ab}}\right| \approx\left|r_{\text {San }}\right|$ after a hiatus of sanidine nucleation and coalescence. In the period of 672 $1848 \mathrm{~h}$ when the issue of sanidine nucleation and coalescence has passed and speculative assumptions of reactive surface areas for albite were no longer necessary, we have,

$$
\begin{aligned}
& \left\{k_{1} / k_{\mathrm{San}}\left(1-e^{-n_{1}\left|\frac{\Delta G_{r}}{R T}\right|^{m 1}}\right)+k_{2} / k_{\mathrm{San}}\left(1-e^{-\left|\frac{\Delta G_{T}}{R T}\right|}\right)^{m 2}\right\}_{\mathrm{Ab}} /\left(e^{\frac{\Delta G_{T}}{R T}}-1\right)_{\mathrm{San}}^{2} \\
& =S_{\mathrm{San}} / S_{\mathrm{Ab}}
\end{aligned}
$$

Since the $k_{j}$ are constant, as well as all other empirical exponent parameters, $S_{j}$ and $\Delta G_{\mathrm{r}}$ are the only temporal variables in the equation and they co-evolved. In our simulation for $672-1848 \mathrm{~h}, S_{\mathrm{Ab}}$ decreased and $S_{\mathrm{San}}$ increased so that $S_{\mathrm{Ab}} /$ $S_{\mathrm{San}}$ decreased with time. The $\Delta G_{\mathrm{r}, \mathrm{San} /} \Delta G_{\mathrm{r}, \mathrm{Ab}}$ decreased correspondingly by decreasing $\Delta G_{\mathrm{r}, \mathrm{San}}$ while maintaining an almost constant $\Delta G_{\mathrm{r}, \mathrm{Ab}}$.

These relationships quantitatively demonstrate the closely coupled or mutual dependant nature of precipitation and dissolution reactions. In fact, these two reactions are inter-locked. They reached a quasi-steady state at $\Delta G_{\mathrm{r}, \mathrm{Ab}} \approx$ $-16 \mathrm{~kJ} \mathrm{~mol}^{-1}$ with a reduction of two orders of magnitude of $r_{\mathrm{Ab}}$ (or a $r_{\mathrm{Ab}} / r_{\mathrm{Ab}}^{\mathrm{o}}$ of 0.01 ) due to the $f\left(\Delta G_{\mathrm{r}}\right)$ effects. $r_{\mathrm{Ab}}$, on the other hand, decreased as $S_{\mathrm{Ab}}$ decreased. However, the system did not move closer to albite equilibrium; albite continued to dissolve at $\Delta G_{\mathrm{r}, \mathrm{Ab}} \approx-16 \mathrm{~kJ} \mathrm{~mol}^{-1}$ until all the albite was dissolved after ca. $3650 \mathrm{~h}$ (Fig. 13). Thus, the system is "arrested", in terms of preventing albite from reaching equilibrium.

The interpretations of the Alek97 experimental data are non-unique. This is particularly true as reactive surface areas and $f\left(\Delta G_{\mathrm{r}}\right)$ co-evolved during these batch reactor experiments. The "experimental" reactive surface areas were deduced from the residues of the $f\left(\Delta G_{\mathrm{r}}\right)$ effects. However, the rate laws for dissolution and precipitation, while affecting the deduced $S_{j}$, do not alter the fact of the cou- pling. During the trials and errors of developing a reaction path model in order to match the experimental data, we had used the first term in Eq. (5) only for albite dissolution and used Alek97's rate law of sanidine dissolution for sanidine precipitation. The omission of the second term resulted in requirements of higher $S_{\mathrm{Ab}}$ for $672-1848 \mathrm{~h}$. In other words, the second term of Eq. (5) only started to affect the results after $360 \mathrm{~h}$. The relationship $\left|r_{\mathrm{Ab}}\right| \approx\left|r_{\text {San }}\right|$ still held and the system was "arrested" at the same quasi-steady state at $\Delta G_{\mathrm{r}, \mathrm{Ab}} \approx-16 \mathrm{~kJ} \mathrm{~mol}^{-1}$.

As we pointed out before, there is no experimental basis for the second term from the Alek97 or the Hellmann and Tisserand (2006) experimental data. The use of the Burch et al. (1993) parameters for the second term, for example, would result in significant revisions of the reactive surface areas in order to match experimental data. However, this is not going to change the outcome of coupling. Likewise, the use of Alek97's rate law for sanidine precipitation had resulted in different fittings of the reactive surface areas for sanidine. The same coupling outcome was obtained $\left(\left|r_{\mathrm{Ab}}\right| \approx\left|r_{\mathrm{San}}\right|\right.$ and the system "arrested" at the same quasisteady state at $\Delta G_{\mathrm{r}, \mathrm{Ab}} \approx-16 \mathrm{~kJ} \mathrm{~mol}^{-1}$ ).

Such a quasi-steady state is important for us to interpret field and laboratory experimental data. First, field samples are difficult to interpret as many coupled reactions in a network could go on simultaneously. Indeed, an inter-locked reaction network is the most likely case for any given field site. Second, on the other hand, observed close coupling of reactions helps us to understand why in some field sites feldspar dissolution rates are orders of magnitude slower than far from equilibrium lab dissolution rates, but by all measured saturation indices of feldspars are still far from equilibrium (White et al., 2001; Georg et al., 2009). This kind of observation was difficult to explain with the TST linear rate law, which requires near equilibrium to achieve significant reduction of rates due to the $f\left(\Delta G_{\mathrm{r}}\right)$ effects.

\subsection{Influences from fluid flow rates}

As pointed out by Zhu and Anderson (2002) and numerous others, most geochemical reaction problems are reactive mass transport problems. It is the fluid flow that brings about mass and heat fluxes that disrupt the equilibrium and drive the reactions. For the subject we have discussed in this paper, we contend that the steady state rates under which chemical reactions proceed in a geological system are the result of competition among the three rates in the simplest case: the rate of dissolution of the primary phase, the rate of precipitation of a secondary phase, and rates of material fluxes associated with fluid flow in a system. The coupling of these three rates is best explored with a reactive mass transport model. However, geological systems are notoriously heterogeneous, with the hydraulic conductivity varying up to 13 orders of magnitude (Freeze and Cherry, 1979). To add uncertainties of hydraulic and geochemical heterogeneities and boundary conditions of a geologic body on top of the uncertainties associated with reactive surface areas and rate laws does not provide much more insight (Zhu, 2009). Instead, we will conduct reactive mass transport in a model system as described below. 
We took the geochemical reaction path model of oligoclase dissolution and kaolinite precipitation from Ganor et al. (2007) and simulated coupled reaction, advection, and dispersion in a one-dimensional (1D) porous media. The model system is represented by a $100 \mathrm{~m}$ strip discretized into 100 cells, each being one meter in length. As a first approximation, a uniform and constant average velocity along the entire cross-section was used. A longitudinal dispersivity of $1 \mathrm{~m}$ was assigned to the model. It was assumed
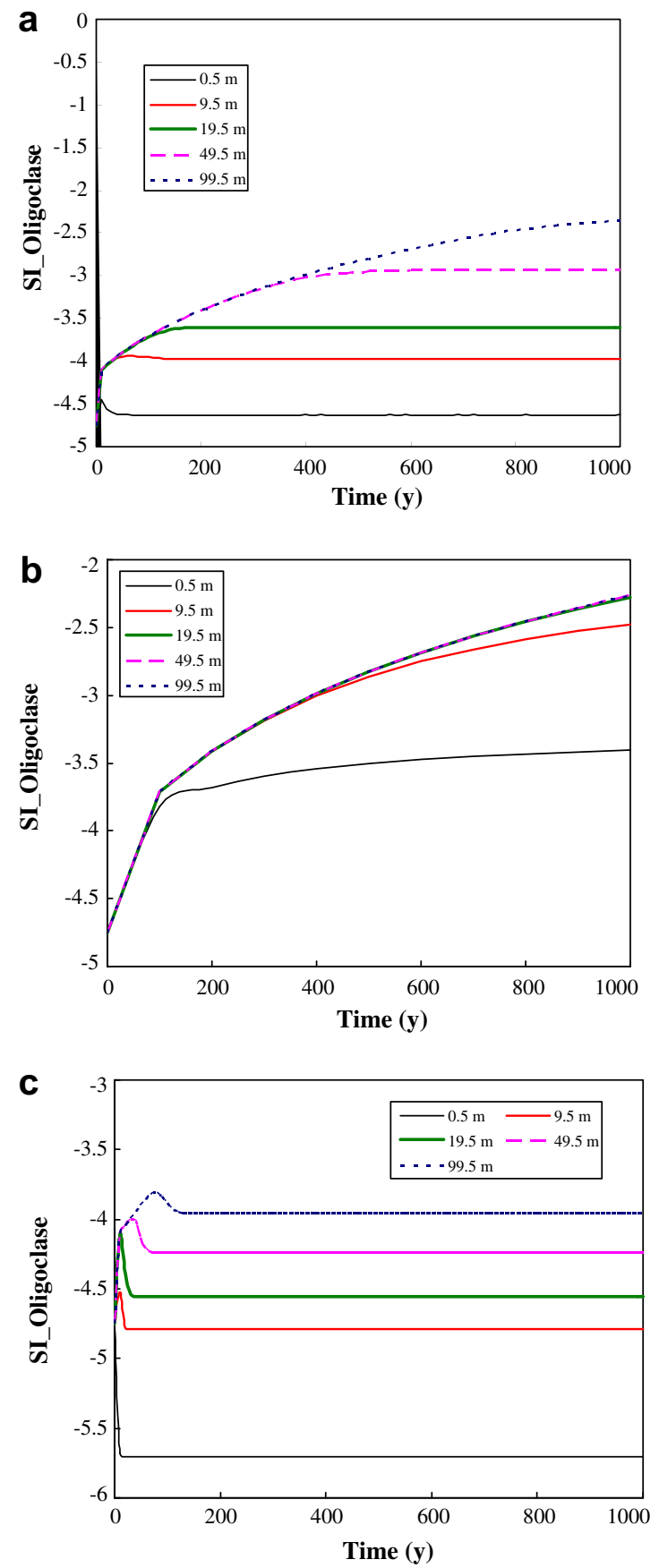

Fig. 18. Calculated saturation indices for oligoclase at different time and space from coupled reactive transport model. (a) Average linear velocity of $0.1 \mathrm{~m} / \mathrm{y}$, (b) $0.01 \mathrm{~m} / \mathrm{y}$, and (c) $1 \mathrm{~m} / \mathrm{y}$. in the study that molecular diffusion is negligible compared to advection and dispersion. Cauchy flux boundary conditions were used for both ends of the 1D strip. Initial pore fluid was taken as the chemistry of the fluid at the end of the reaction path simulation in Ganor et al. (2007), and inflow water into the column was taken as the chemistry of initial fluid from Ganor et al. (2007). All geochemical parameters used were the same as those in Ganor et al. (2007), with exception that the $k_{1}, k_{2}$ in Eq. (5), which were scaled two orders of magnitude higher. The advection, dispersion, and reaction of aqueous components under the initial and boundary conditions (described above) were simulated by using PhreeqC Version 2.3, a one-dimensional finite-difference model (Parkhurst and Appello, 1999).

Three different average linear velocities were used for the three scenarios. Fig. 18 shows the results of coupling among the dissolution, precipitation, and flow rates in terms of SI for oligoclase at different time and space. For the base case of $0.1 \mathrm{~m} / \mathrm{y}$, different levels of steady state SI were established at different locations along the 1D strip after some time, with lower SI near the entrance (flushed by a dilute solution). These SI values were fed back to $f\left(\Delta G_{\mathrm{r}}\right)$ in the rate laws for oligoclase and kaolinite, which, in turn, determined the reaction rates, resulting in steady state concentrations of aqueous constituents at specific spatial locations.

For a slower flow rate $(0.01 \mathrm{~m} / \mathrm{y})$, steady state was generally not achieved within 1000 years of the simulation period. Here we see that the steady state had a higher SI for oligoclase as compared to the base case. In other words, the smaller solute fluxes from upstream brought about less dilution of the pore fluids in the domain as compared to the base case, resulting in less influence from transport. For a faster flow rate $(1 \mathrm{~m} / \mathrm{y})$, we see the transport effects are stronger.

In all three scenarios, steady states were established at different levels of SI, resulting in different rates of dissolution and precipitation reactions in the time-space domain. However, the ratios of oligoclase dissolution and kaolinite precipitation rates remained 1.626, as in the batch system case (Ganor et al., 2007). Therefore, the simulation results demonstrated the coupling among dissolution, precipitation, and flow rates. Instead of reaching a single steady state that was determined by the ratios of effective rate constants, surface areas, and rate laws, a series of steady state rates were established at different locations of the domain, even in this initially geochemically homogeneous media. The time to achieve the steady state and the SI and reaction rates of the steady state was a function of the flow rates, assuming the geochemical parameters are the same in all scenarios.

\section{CONCLUSIONS AND REMARKS}

The geochemical modeling results in the preceding sections lend support to the Zhu-Blum-Veblen hypothesis for explaining the apparent field-lab discrepancy (Zhu et al., 2004). In the literature, the majority of laboratory studies have focused on measuring dissolution rates under which secondary mineral precipitation were suppressed while the majority of field weathering studies have at- 
tempted to derive dissolution rates only, without information of the precipitation rates and as if the dissolution rates were independent from other reactions in the reaction network. Not surprisingly, the derived field rates are orders of magnitude slower than the far from equilibrium lab rates. The ZBV hypothesis has now been developed in more detail:

(a) Experiments show that the congruent dissolution stage for feldspar dissolution is short because of the low solubility of aluminum silicate minerals. Secondary mineral(s) started to precipitate after only a small amount of primary minerals are dissolved. The same is expected in the field. In fact, it would be difficult to find field situations that secondary mineral precipitation is not present. Therefore, we must always look at the primary mineral dissolution as part of the reaction network.

(b) Previously, we have shown qualitatively that the partial equilibrium assumption does not hold in these experimental systems (Zhu and Lu, 2009). The numerical reaction path modeling results in this study provided more quantitative evidence. Although many simplifications were made in the reaction path model, and the reaction path models presented above are by no means unique representations of the experimental data, the basic conclusion regarding the lack of partial equilibrium stands. In a partial equilibrium system, the irreversible dissolution of feldspar is the driving force. We show that when partial equilibrium between secondary minerals and an aqueous solution does not hold, the precipitation of secondary minerals is the limiting step, which caps the dissolution rate of the primary mineral. The absence of partial equilibrium under hydrothermal conditions $\left(200-300^{\circ} \mathrm{C}\right)$ indicates that partial equilibrium is also not attained at ambient weathering conditions even though the secondary minerals are different.

(c) A quasi-steady state is reached when $k_{1}^{*} / k_{2}^{*}>q$, where $k_{1}^{*}$ and $k_{2}^{*}$ demote the effective rate constants in mol s${ }^{-1} \mathrm{kgw}^{-1}$ of the dissolution and precipitation reactions, respectively, and $q$ is a threshold value. At the quasi-steady state, the ratios for dissolution and precipitation rates are fixed when the rates are expressed in unit of mol s${ }^{-1} \mathrm{kgw}^{-1}$, and the dissolution reaction proceeds at a fixed $\Delta G_{\mathrm{r}}$. The values of this ratio are a function of the overall reaction stoichiometry, e.g., almost unity in the albite dissolution-sanidine precipitation experiments of Alekseyev et al. (1997) and 1.626 for oligoclase dissolutionkaolinite precipitation in the simulation of Ganor et al. (2007). The steady state dissolution rate, $r^{\text {ss }}$, expressed as mol s${ }^{-1} \mathrm{kgw}^{-1}$, may be orders of magnitude slower than the far from equilibrium rate, $r^{\circ}$. For the experiments by Alekseyev et al. (1997) and Fu et al. (2009), $r^{\mathrm{ss}} / r^{\mathrm{o}} \approx 0.01$ at 300 and $200{ }^{\circ} \mathrm{C}$. With increasing $k_{1}^{*} / k_{2}^{*}$ (increasingly slower initial precipitation with respect to dissolution), the steady state dissolution rates of the primary mineral also decrease (Fig. 3 of Zhu, 2009).

(d) Under which conditions the system reaches a steady state with regard to coupled dissolution-precipitation reactions is also determined by the $r-\Delta G_{\mathrm{r}}$ relationships for the dissolution and precipitation reactions. With the experimentally defined sigmoidal shape relationships for albite, the influence of the $\Delta G_{\mathrm{r}}$ term takes place in solutions more undersaturated with respect to the dissolving primary mineral than was previously thought, i.e., using the $f\left(\Delta G_{\mathrm{r}}\right)$ function of transition state theory; it now is not required to be very close to equilibrium for dissolution rates to be reduced by orders of magnitude due to coupling effects. In the case of albite dissolution-sanidine precipitation at $300^{\circ} \mathrm{C}$ (Alekseyev et al., 1997), the $\Delta G_{\mathrm{r}}$ for albite dissolution-sanidine precipitation reactions were locked at $\Delta G_{\mathrm{r}, \mathrm{Ab}} \sim-16$ $\mathrm{kJ} \mathrm{mol}^{-1}$. In contrast, the TST linear rate law would require near equilibrium conditions with respect to the primary minerals to reach orders of magnitude reduction of dissolution rate due to the $\Delta G_{\mathrm{r}}$ effects. Field data show that field rates are orders of magnitude slower than the far from equilibrium lab rates, whereas the groundwater is not very close to saturation with feldspar (White et al., 2001; Georg et al., 2009).

(e) The potential effects of fluid flow on the coupling of reactions were demonstrated with reactive mass transport modeling in a system resembling that described by Ganor et al. (2007). The results of solute fluxes generated a series of steady states (i.e., SI, aqueous concentrations, and reaction rates) at different locations in the computational domain, even though the media was assumed to be geochemically homogeneous. The time-space distribution and levels of quasi-steady states are determined by the flow rates for a given kinetics model. A range of rates can be sampled in a field system for samples with close spatial proximity, as well as transient chemical states in a system. Therefore, slow clay precipitation effectively reduces feldspar dissolution rates by orders of magnitude, in a fashion consistent with laboratory rates, transition state theory, and field observations. Furthermore, "close to equilibrium" is probably the most quoted explanation for the apparent discrepancy. However, how this explanation can work quantitatively was not explained before. Our hypothesis provides a quantitative explanation.

The control of feldspar dissolution by the precipitation kinetics of the secondary minerals reconciles many of the apparent discrepancies between laboratory experimental rates and field measurements, and explains field observations that previously appeared inconsistent. It explains slow but persistent feldspar dissolution in sandstone aquifers (Zhu, 2005 for the Navajo sandstone aquifer in northeastern Arizona); why smectite coatings occur on all sediment grains, not only on feldspars (Zhu et al., 2006); why kaolinite is preserved and co-exists with smectite in natural systems over hundreds of thousands to millions years (Zhu et al., 2006). Our hypothesis shifts the paradigm from debate about feldspar dissolution kinetics to the formation kinetics of secondary phases, and opens up new possibilities for laboratory and field experiments to unravel the rates of overall aluminosilicate weathering reactions.

So far, our work has only focused on the coupling of one dissolution reaction with one precipitation reaction. In field situations, several dissolution and precipitation reactions may operate simultaneously. The coupling effects in the reaction network can become extremely complex. The experimental data at elevated temperatures 200 and $300{ }^{\circ} \mathrm{C}$ showed maximally two orders of magnitude reduction due to the coupled reaction effects. Our modeling study 
has clearly identified the research needs of the rate laws in the near equilibrium regions, rate law for precipitation reactions, and more studies of reactive surface areas.

Another source of retardation of dissolution rates in the field can come from surface passivation. Zhu et al. (2006) found a thin 10-50 $\mathrm{nm}$ amorphous layer on the K-feldspar surfaces in the Jurassic Navajo sandstone in Arizona. Whether such a layer is widespread for minerals that have been in contact with water for thousands to million years and what the role this layer plays is currently unclear.

\section{ACKNOWLEDGMENTS}

This work is supported by the U.S. Department of Energy under Award No. DE-FG26-04NT42125 and partially by the National Science Foundation under Award No. EAR0423971 and EAR0509775 to C.Z. Any opinions, findings, and conclusions or recommendations expressed in this material, however, are those of the authors and do not necessarily reflect the views of the United States Government or any agency thereof. C.Z. also wishes to acknowledge his Fulbright Grant in Norway and University of Oslo as his host, and his sabbatical leave hosts University of California - Berkeley and ETH, during which time the writing of this paper finally became possible. We are especially grateful to Tom Wolery and two anonymous reviewers for constructive comments.

\section{REFERENCES}

Aagaard P. and Helgeson H. C. (1982) Thermodynamic and kinetic constraints on reaction rates among minerals and aqueous solutions. I. Theoretical considerations. Am. J. Sci. 282, 237285.

Alekseyev V. A., Medvedeva L. S., Prisyagina N. I., Meshalkin S. S. and Balabin A. I. (1997) Change in the dissolution rates of alkali feldspars as a result of secondary mineral precipitation and approach to equilibrium. Geochim. Cosmochim. Acta 61, $1125-1142$

Banfield J. F. and Barker W. W. (1994) Direct observation of reactant-product interfaces formed in natural weathering of exsolved, defective amphibole to smectite - evidence for episodic, isovolumetric reactions involving structural inheritance. Geochim. Cosmochim. Acta 58, 1419-1429.

Banfield J. F. and Eggleton R. A. (1990) Analytical transmission electron-microscope studies of plagioclase, muscovite, and Kfeldspar weathering. Clay Clay Mineral. 38, 77-89.

Banfield J. F., Jones B. F. and Veblen D. R. (1991) An AEM-TEM study of weathering and diagenesis, Albert Lake, Oregon. I. Weathering reactions in the volcanics. Geochim. Cosmochim. Acta 55, 2781-2793.

Beig M. S. and Lüttge A. (2006) Albite dissolution kinetics as a function of distance from equilibrium: implications for natural feldspar weathering. Geochim. Cosmochim. Acta 70, 1402-1420.

Bénézeth P., Palmer D. A. and Wesolowski D. J. (2008) Dissolution/precipitation kinetics of boehmite and gibbsite: application of a $\mathrm{pH}$-relaxation technique to study near-equilibrium rates. Geochim. Cosmochim. Acta 72, 2429-2453.

Blum A. and Stillings L. (1995) Feldspar dissolution kinetics. In Chemical Weathering Rates of Silicate Minerals, vol. 31 (eds. S. L. Brantley and A. R. White). Mineralogical Society of America, Washington, DC, pp. 291-346.

Brantley S. L. (1992) Kinetics of dissolution and precipitationexperimental and field results. In Proceedings of the Seventh International Conference on Water-Rock Interactions (eds. Y.
Kharaka and A. Maest), Park City, Utah. Balkema, Rotterdam.

Brantley S. L. and Stillings L. (1996) Feldspar dissolution at $25^{\circ} \mathrm{C}$ and low pH. Am. J. Sci. 296, 101-127.

Braunauer S., Emmett P. H. and Teller E. (1938) Adsorption of gases in mutlimolecular layers. J. Am. Chem. Soc. 60, 309-319.

Burch T. E., Nagy K. L. and Lasaga A. C. (1993) Free energy dependence of albite dissolution kinetics at $80^{\circ} \mathrm{C}$ and $\mathrm{pH} 8.8$. Chem. Geol. 105, 137-162.

Burton W. K., Cabrera N. and Frank F. C. (1951) The growth of crystals and the equilibrium structure of their surfaces. $R$. Soc. Lond. Philos. Trans. 243, 299-358.

Busenberg E. and Clemency C. V. (1976) The dissolution kinetics of feldspars at $25^{\circ} \mathrm{C}$ and $1 \mathrm{~atm} \mathrm{CO}_{2}$ partial pressure. Geochim. Cosmochim. Acta 40, 41-49.

Cama J., Ganor J., Ayora C. and Lasaga C. A. (2000) Smetite dissolution kinetics at $80^{\circ} \mathrm{C}$ and $\mathrm{pH}$ 8.8. Geochim. Cosmochim. Acta 64, 2701-2717.

Chou L. and Wollast R. (1984) Study of the weathering of albite at room temperature and pressure with a fluidized bed reactor. Geochim. Cosmochim. Acta 48, 2205-2217.

Chou L. and Wollast R. (1985) Steady-state kinetics and dissolution mechanisms of albite. Am. J. Sci. 285, 963-993.

Christoffersen J. and Christoffersen M. R. (1976) The kinetics of dissolution of calcium sulphate dihydrate in water. J. Cryst. Growth 35, 79-88.

Correns C. W. (1940) Die Chemische Verwitterung der Silikate. Nature 28, 369-376.

Correns C. W. and von Engelhardt W. (1938) Neue Untersuchungen uber die Verwiterung des Kalifeldspates. Chem. Erde 12, 122.

Cubillas P., Kohler S., Prieto M., Causserand C. and Oelkers E. H. (2005) How do mineral coating affect dissolution rates? An experimental study of coupled $\mathrm{CdCO}_{3}$ dissolution- $\mathrm{CdCO}_{3}$ precipitation. Geochim. Cosmochim. Acta 69, 5459-5476.

Drever J. I. and Clow D. W. (1995) Weathering rates in catchments. In Chemical Weathering Rates of Silicate Minerals, vol. 31 (eds. A. F. White and S. L. Brantley). Mineralogical Society of America, pp. 463-481.

Freeze R. A. and Cherry J. A. (1979) Groundwater. Prentice-Hall, New York.

Fritz B. and Noguera C. (2009) Mineral precipitation kinetics. In Thermodynamics and Kinetics of Water-Rock Interaction (eds. E. H. Oelkers and J. Schott), pp. 371-409. vol. 70. Mineralogical Society of America.

Fu Q., Lu P., Konishi H., Dilmore R., Xu H., Seyfried, Jr., W. E. and Zhu C. (2009) Coupled alkali-feldspar dissolution and secondary mineral precipitation in batch systems: 1 . New experiment data at $200^{\circ} \mathrm{C}$ and 300 bars. Chem. Geol. 91, 955964.

Ganor J., Mogollon J. L. and Lasaga A. C. (1995) The effect of pH on kaolinite dissolution rates and on activation energy. Geochim. Cosmochim. Acta 59, 1037-1052.

Ganor J., Mogollon J. L. and Lasaga A. C. (1999) Kinetics of gibbsite dissolution under low ionic strength conditions. Geochim. Cosmochim. Acta 63, 1635-1651.

Ganor J., Lu P., Zheng Z. and Zhu C. (2007) Bridging the gap between laboratory measurements and field estimations of weathering using simple calculations. Environ. Geol. 53, 599610.

Garrels R. M. and Howard D. F. (1957) Reactions of feldspar and mica with water at low temperatures and pressures. In The Sixth National Conference on Clays and Glay Minerals, vol. 67. Pergamon Press, New York, Berkeley, California. pp. 68-88.

Gautier J.-M., Oelkers E. H. and Schott J. (1994) Experimental study of K-feldspar dissolution rates as a function of chemical 
affinity at $150{ }^{\circ} \mathrm{C}$ and $\mathrm{pH}$ 9. Geochim. Cosmochim. Acta 58, 4549-4560.

Gautier J. M., Oelkers E. H. and Schott J. (2001) Are quartz dissolution rates proportional to B.E.T. surface areas? Geochim. Cosmochim. Acta 65, 1059-1070.

Georg R. B., Zhu C., Reynolds R. C. and Halliday A. N. (2009) Stable silicon isotopes of groundwater, feldspars, and clay coatings in the Navajo Sandstone aquifer, Black Mesa, Arizona, USA. Geochim. Cosmochim. Acta 73, 2229-2241.

Haar L., Gallagher J. S. and Kell G. S. (1984) NBS/NRC Steam Tables: Thermodynamic and Transport Properties and Computer Programs for Vapor and Liquid States of Water in SI Units. Hemisphere Publishing Corporation, New York, p. 320.

He S., Oddo J. E. and Tomson M. B. (1994) The seeded growth of calcium sulfate dihydrate crystals in $\mathrm{NaCl}$ solutions up to $6 \mathrm{~m}$ and $90^{\circ}$ C. J. Colloid Interf. Sci. 163, 372-378.

Helgeson H. C. (1968) Evaluation of irreversible reactions in geochemical processes involving minerals and aqueous solutions-1. Thermodynamic relations. Geochim. Cosmochim. Acta 32, 853-877.

Helgeson H. C. (1971) Kinetics of mass transfer among silicates and aqueous solutions. Geochim. Cosmochim. Acta 35, 421-469.

Helgeson H. C. (1972) Kinetics of mass transfer among silicates and aqueous solutions: correction and clarification. Geochim. Cosmochim. Acta 36, 1067-1070.

Helgeson H. C. (1979) Mass transfer among minerals and hydrothermal solutions. In Geochemistry of Hydrothermal Ore Deposits (ed. H. L. Barnes). John Wiley \& Sons, New York, pp. 568-610.

Helgeson H. C., Garrels R. M. and Mackenzie F. T. (1969) Evaluation of irreversible reactions in geochemical processing involving minerals and aqueous solutions-II. Applications. Geochim. Cosmochim. Acta 33, 455-481.

Helgeson H. C., Brown T. H., Nigrini A. and Jones T. A. (1970) Calculation of mass transfer in geochemical processes involving aqueous solutions. Geochim. Cosmochim. Acta 34, 569-592.

Helgeson H. C., Delany J. M., Nesbitt H. W. and Bird D. K. (1978) Summary and critique of the thermodynamic properties of rock forming minerals. Am. J. Sci. 278A, 569-592.

Helgeson H. C., Murphy W. M. and Aagaard P. (1984) Thermodynamic and kinetic constraints on reaction rates among minerals and aqueous solutions II. Rate constants, effective surface area, and the hydrolysis of feldspar. Geochim. Cosmochim. Acta 48, 2405-2432.

Hellmann R. (1994) The albite-water system: Part I. The kinetics of dissolution as a function of $\mathrm{pH}$ at 100,200 , and $300{ }^{\circ} \mathrm{C}$. Geochim. Cosmochim. Acta 58, 595-611.

Hellmann R. (1997) The albite-water system: Part III. Characterization of leached and hydrogen-enriched layers formed at $300^{\circ} \mathrm{C}$ using $\mathrm{MeV}$ ion beam techniques. Geochim. Cosmochim. Acta 61, 1575-1594.

Hellmann R. and Tisserand D. (2006) Dissolution kinetics as a function of the Gibbs free energy of reaction: an experimental study based on albite feldspar. Geochim. Cosmochim. Acta 70, 364-383.

Hellmann R., Eggleston C. R., Hochella M. F. and Crerar D. A. (1990) The formation of leached layers on albite surfaces during dissolution under hydrothermal conditions. Geochim. Cosmochim. Acta 54, 1267-1281.

Hemingway B. S., Robie R. A. and Apps J. A. (1991) Revised values for the thermodynamic properties of boehmite, $\mathrm{AlO}(\mathrm{OH})$, and related species and phases in the system $\mathrm{Al}-\mathrm{H}-$ O. Am. Mineral. 445, 457.

Hereford A. G., Keating E., Guthrie G. and Zhu C. (2007) Reactions and reaction rates in the aquifer beneath Pajarito Plateau, north-central New Mexico. Environ. Geol. 52, 965-977.
Ho P. C., Bianchi H., Palmer D. A. and Wood R. H. (2000) Conductivity of dilute aqueous electrolyte solutions at high temperatures and pressures using a flow cell. J. Solution Chem. 29, 217-235.

Hoch A. R., Reddy M. M. and Aiken G. R. (2000) Calcite crystal growth inhibition by humic substances with emphasis on hydrophobic acids from the Florida Everglades. Geochim. Cosmochim. Acta 64, 61-72.

Holland T. J. B. and Powell R. (1998) An internally consistent thermodynamic data set for phases of petrological interest. $J$. Metamorph. Geol. 16, 309-343.

Labotka T. C., Cole D. R., Fayek M., Riciputi L. R. and Stadermann F. J. (2004) Coupled cation and oxygen-isotope exchange between alkali feldspar and aqueous chloride solution. Am. Mineral. 89, 1822-1825.

Lasaga A. C. (1981a) Rate laws of chemical reactions. In Kinetics of Geochemical Processes, vol. 8 (eds. A. C. Lasaga and R. J. Kirkpatrick). Mineralogical Society of America, Washington, DC, pp. 1-68.

Lasaga A. C. (1981b) Transition state theory. In Kinetics of Geochemical Processes, vol. 8 (eds. A. C. Lasaga and R. J. Kirkpatrick). Mineralogical Society of America, Washington, DC, pp. 135-169.

Lasaga A. C., Soler J. M., Ganor J., Burch T. E. and Nagy K. L. (1994) Chemical weathering rate laws and global geochemical cycles. Geochim. Cosmochim. Acta 58, 2361-2386.

Liu S. T. and Nancollas G. H. (1975) A kinetic and morphological study of the seeded growth of calcium sulfate dihydrate in the presence of additives. J. Colloid Interf. Sci. 52, 593-601.

Luce R. W., Bartlett R. W. and Parks G. A. (1972) Dissolution kinetics of magnesium silicates. Geochim. Cosmochim. Acta 36, $35-50$.

McCollom T. M. and Shock E. L. (1997) Geochemical constraints on chemolithoautotrophic metabolism by microorganisms in seafloor hydrothermal systems. Geochim. Cosmochim. Acta 61, 4375-4391.

Metz V., Raanan H., Pieper H., Bosbach D. and Ganor J. (2005) Towards the establishment of a reliable proxy for the reactive surface area of smectite. Geochim. Cosmochim. Acta 69, 25812591.

Nagy K. L. (1995) Dissolution and precipitation kinetics of sheet silicates. In Chemical Weathering Rates of Silicate Minerals (eds. A. F. White and S. L. Brantley), pp. 173-225. vol. 31. Mineralogical Society of America.

Nagy K. L. and Lasaga A. C. (1992) Dissolution and precipitation kinetics of gibbsite at $80^{\circ} \mathrm{C}$ and pH-3 - the dependence on solution saturation state. Geochim. Cosmochim. Acta 56, 3093-3111.

Nagy K. L. and Lasaga A. C. (1993) Kinetics of simultaneous kaolinite and gibbsite precipitation. Geochim. Cosmochim. Acta 57, 4329-4337.

Nagy K. L., Blum A. E. and Lasaga A. C. (1991) Dissolution and precipitation kinetics of kaolinite at $80^{\circ} \mathrm{C}$ and $\mathrm{pH}$ 3: the effect of deviation from equilibrium. Am. J. Sci. 291, 649-686.

Nesbitt H. W. and Skinner W. M. (2001) Early development of Al, $\mathrm{Ca}$, and $\mathrm{Na}$ compositional gradients in labradorite leached in pH 2 HCI solutions. Geochim. Cosmochim. Acta 65, 715-727.

Nielsen A. E. (1964) Kinetics of Precipitation. Pergamon, Oxford.

Nugent M. A., Brantley S. L., Pantano C. G. and Maurice P. A. (1998) The influence of natural mineral coatings on feldspar weathering. Nature 395, 588-591.

Oelkers E. H. (2001) General kinetic description of multioxide silicate mineral and glass dissolution. Geochim. Cosmochim. Acta 65, 3703-3719.

Oelkers E. H. and Helgeson H. C. (1990) Triple-ion anions and polynuclear complexing in supercritical electrolyte-solutions. Geochim. Cosmochim. Acta 54, 727-738. 
Oelkers E. H., Schott J. and Devidal J. L. (1994) The effect of aluminum, $\mathrm{pH}$, and chemical affinity on the rates of aluminosilicate dissolution reactions. Geochim. Cosmochim. Acta 58, 2011-2024.

Paces T. (1973) Steady-state kinetics and equilibrium between ground water and granitic rocks. Geochim. Cosmochim. Acta 37, 2641-2663.

Parkhurst D. L. and Appello A. A. J. (1999) User's guide to PHREEQC (version 2) - a computer program for speciation, batch-reaction, one dimensional transport, and inverse geochemical modeling. U.S. Geological Survey. Water-Resource Investigation Report 99-4259. p. 312.

Prigogine I. and Defay R. (1965) Chemical Thermodynamics. Longmans Green, London.

Putnis A. (2002) Mineral replacement reactions: from macroscopic observations to microscopic mechanisms. Mineral. Mag. 66, 689-708.

Reed M. H. and Spycher N. F. (1984) Calculation of pH and mineral equilibria in hydrothermal waters with application to geothermometry and studies of boiling and dilution. Geochim. Cosmochim. Acta. 48, 1479-1492.

Schramke J. A., Kerrick D. M. and Lasaga A. C. (1987) The reaction muscovite + quartz $=$ andalusite $+\mathrm{K}$-feldspar + water. Part I. Growth kinetics and mechanism. Am. J. Sci. 287, 517-559.

Siegel D. I. and Pfannkuch H. O. (1984) Silicate dissolution influence on Filson Creek chemistry, northeastern Minnesota. Geol. Soc. Am. Bull. 95, 1446-1453.

Stillings L. L., Brantley S. L. and Machesky M. L. (1995) Proton adsorption at an adularia feldspar surface. Geochim. Cosmochim. Acta 59, 1473-1482.

Sverjensky D. A., Shock E. L. and Helgeson H. C. (1997) Prediction of the thermodynamic properties of aqueous metal complexes to $5 \mathrm{~Kb}$ and $1000{ }^{\circ} \mathrm{C}$. Geochim. Cosmochim. Acta 61, 1359-1412.

Tagirov B. and Schott J. (2001) Aluminum speciation in crustal fluids revisited. Geochim. Cosmochim. Acta 65, 3965-3992.

Taylor A. S., Blum J. D. and Lasaga A. C. (2000) The dependence of labradorite dissolution and $\mathrm{Sr}$ isotope release rates on solution saturation state. Geochim. Cosmochim. Acta 64, 23892400.

Velbel M. A. (1990) Influence of temperature and mineral surface characteristics on feldspar weathering rates in natural and artificial systems: a first approximation. Water Resour. Res. 26, 3049-3053.

Weijnen M. P. C. and Van Rosmalen G. M. (1986) Adsorption of phosphonates on gypsum crystals. J. Cryst. Growth 79, 157168.

White A. F., Bullen T. D., Schulz M. S., Blum A. E., Huntington T. G. and Peters N. E. (2001) Differential rates of feldspar weathering in granitic regoliths. Geochim. Cosmochim. Acta 65, 847-869.

Witkamp G. J., Van der Eerden J. P. and Van Rosmalen G. M. (1990) Growth of gypsum: I. Kinetics. J. Cryst. Growth 102, 281-289.

Wolery T. J. (1992) EQ3/6, A software package for geochemical modeling of aqueous systems: Package overview and installation guide (version 7.0). URCL-MA-110662-PT-I, Livermore, Lawrence Livermore Laboratory, California Univ., California.

Zhang J. and Nancollas G. H. (1992) Influence of calcium/sulfate molar ratio on the growth rate of calcium sulfate dihydrate at constant supersaturation. J. Cryst. Growth 118, 287-294.

Zhu C. (2005) In situ feldspar dissolution rates in an aquifer. Geochim. Cosmochim. Acta 69, 1435-1453.

Zhu C. (2009) Geochemical modeling of reaction paths and geochemical reaction networks. In Thermodynamics and Kinetics of Water-Rock Interaction, vol. 70 (eds. E. H. Oelkers and J. Schott). Mineralogical Society of America, pp. 533-569.

Zhu C. and Anderson G. M. (2002) Environmental Applications of Geochemical Modeling. Cambridge University Press, London.

Zhu C. and Lu P. (2009) Coupled alkali feldspar dissolution and secondary mineral precipitation in batch systems: 3. Saturation indices of product minerals and reaction paths. Geochim. Cosmochim. Acta 73, 3171-3200.

Zhu C., Blum A. E. and Veblen D. R. (2004) Feldspar dissolution rates and clay precipitation in the Navajo aquifer at Black Mesa, Arizona, USA. In Water-Rock Interaction (eds. R. B. Wanty and R. R. I. Seal). A.A. Balkema, Saratoga Springs, New York, pp. 895-899.

Zhu C., Veblen D. R., Blum A. E. and Chipera S. J. (2006) Naturally weathered feldspar surfaces in the Navajo Sandstone aquifer, Black Mesa, Arizona: electron microscopic characterization. Geochim. Cosmochim. Acta 70, 4600-4616.

Associate editor: Johnson R. Haas 